\title{
Elevated mutant dynorphin A causes Purkinje cell loss and motor dysfunction in spinocerebellar ataxia type 23
}

\author{
Cleo J. L. M. Smeets, ',* Justyna Jezierska, ',* Hiroyuki Watanabe, ${ }^{2}$ Anna Duarri, ' \\ Michiel R. Fokkens, ' Michel Meijer, ${ }^{3}$ Qin Zhou, ${ }^{2}$ Tania Yakovleva, ${ }^{2}$ Erik Boddeke, ${ }^{3}$ \\ Wilfred den Dunnen, ${ }^{4}$ Jan van Deursen, ${ }^{5}$ Georgy Bakalkin, ${ }^{3}$ Harm H. Kampinga, ${ }^{6}$ \\ Bart van de Sluis ${ }^{7}$ and Dineke S. Verbeek'
}

*These authors contributed equally to this work.

Spinocerebellar ataxia type 23 is caused by mutations in PDYN, which encodes the opioid neuropeptide precursor protein, prodynorphin. Prodynorphin is processed into the opioid peptides, $\alpha$-neoendorphin, and dynorphins A and B, that normally exhibit opioid-receptor mediated actions in pain signalling and addiction. Dynorphin A is likely a mutational hotspot for spinocerebellar ataxia type 23 mutations, and in vitro data suggested that dynorphin A mutations lead to persistently elevated mutant peptide levels that are cytotoxic and may thus play a crucial role in the pathogenesis of spinocerebellar ataxia type 23 . To further test this and study spinocerebellar ataxia type 23 in more detail, we generated a mouse carrying the spinocerebellar ataxia type 23 mutation $\mathrm{R} 212 \mathrm{~W}$ in PDYN. Analysis of peptide levels using a radioimmunoassay shows that these PDYN ${ }^{\mathrm{R} 212 \mathrm{~W}}$ mice display markedly elevated levels of mutant dynorphin A, which are associated with climber fibre retraction and Purkinje cell loss, visualized with immunohistochemical stainings. The $P D Y \mathrm{~N}^{\mathrm{R} 212 \mathrm{~W}}$ mice reproduced many of the clinical features of spinocerebellar ataxia type 23 , with gait deficits starting at 3 months of age revealed by footprint pattern analysis, and progressive loss of motor coordination and balance at the age of 12 months demonstrated by declining performances on the accelerating Rotarod. The pathologically elevated mutant dynorphin A levels in the cerebellum coincided with transcriptionally dysregulated ionotropic and metabotropic glutamate receptors and glutamate transporters, and altered neuronal excitability. In conclusion, the PDYN ${ }^{\mathrm{R} 212 \mathrm{~W}}$ mouse is the first animal model of spinocerebellar ataxia type 23 and our work indicates that the elevated mutant dynorphin A peptide levels are likely responsible for the initiation and progression of the disease, affecting glutamatergic signalling, neuronal excitability, and motor performance. Our novel mouse model defines a critical role for opioid neuropeptides in spinocerebellar ataxia, and suggests that restoring the elevated mutant neuropeptide levels can be explored as a therapeutic intervention.

1 Department of Genetics, University of Groningen, University Medical Centre Groningen, Groningen, The Netherlands

2 Division of Biological Research on Drug Dependence, Department of Pharmaceutical Biosciences, Uppsala University, Uppsala, Sweden

3 Department of Medical Physiology, University of Groningen, University Medical Centre Groningen, Groningen, The Netherlands

4 Department of Pathology, University of Groningen, University Medical Centre Groningen, Groningen, The Netherlands

5 Department of Paediatric and Adolescent Medicine, Mayo Clinic, Rochester, Minnesota, USA

6 Department of Cell Biology, University of Groningen, University Medical Centre Groningen, Groningen, The Netherlands

7 Department of Paediatrics, Molecular Genetics Section, University of Groningen, University Medical Centre Groningen, Groningen, The Netherlands 
Correspondence to: D. S. Verbeek, Department of Genetics, PO box 30001, 9700 RB Groningen, The Netherlands E-mail: d.s.verbeek@umcg.nl

Keywords: prodynorphin; opioid; glutamate; neurodegeneration; spinocerebellar ataxia

Abbreviations: AMPA-R = $\alpha$-amino-3-hydroxy-5-methylisoxazole-4-propionate receptor; NMDA-R = N-methyl-D-aspartate receptor; SCA = spinocerebellar ataxia; Sim/Crus = lobules simplex and CrusI and CrusII ansiform lobules; vGlut $2=$ vesicular glutamate transporter 2

\section{Introduction}

PDYN is the precursor protein for the opioid peptides $\alpha$-neoendorphin, dynorphin A, and dynorphin B. The actions of these neuropeptides are mediated via the kappa-opioid receptor (encoded by OPRK1) (Akil et al., 1984; Merg et al., 2006). Dynorphins regulate pain, substance dependence, and stress-induced responses via opioidreceptor signalling (Hauser et al., 2005; Chavkin, 2013). However, dynorphin A can also exhibit non-opioidmediated neurotoxic effects, as elevated peptide levels cause allodynia, paralysis and neuronal loss in the spinal cord of mice, which could not be blocked by an opioid antagonist (Herman et al., 1980; Walker et al., 1982; Hauser et al., 2005). Dynorphin A was shown to cause pronounced cell death that was dependent on the presence of NMDA-Rs (N-methyl D-aspartate receptors) (Tan-No et al., 2001). Additional neurotoxic mechanisms of dynorphins may be mediated via numerous receptors and/ or channels such as AMPA-Rs ( $\alpha$-amino-3-hydroxy-5-methylisoxazole-4-propionate receptors) (Singh et al., 2003) or ASIC1a (acid-sensing ion 1a) channels (Sherwood and Askwith, 2009).

Mutations in PDYN were shown to cause spinocerebellar ataxia type 23 (SCA23), a slowly progressive, autosomal dominant neurodegenerative disorder (Bakalkin et al., 2010). SCA23 patients suffer from relatively slowly progressive impairment of their motor coordination, and a fairly pure cerebellar ataxia due to Purkinje cell death in the cerebellum (Verbeek et al., 2004). The majority of SCA23 mutations located in the highly conserved dynorphin A-coding region lead to enhanced levels of mutant dynorphin A in cells, either due to higher peptide production or increased peptide stability (Bakalkin et al., 2010). These mutant dynorphin A peptides displayed neurotoxic properties in cultured striatal neurons (Bakalkin et al., 2010), and induce pathological pain when injected into mice in femtomolar doses (Watanabe et al., 2012). Although the mechanism is unclear, recent studies indicate that these mutant peptides interact with and penetrate cellular membranes in vitro, and thus lead to cell death (Madani et al., 2011; Björnerås et al., 2013). Increased expression of PDYN and its neuropeptides have also been implicated in age-related decline of cognition and memory (Kotz et al., 2004; Ménard et al., 2013).
Furthermore, elevated dynorphin A levels have been linked to the pathology of Alzheimer's disease (Yakovleva et al., 2007), supporting a crucial role for elevated opioid neuropeptides levels in the aetiology of neurodegenerative disorders.

To reveal the causality between mutations in PDYN and SCA23, we generated transgenic mice ubiquitously expressing wild-type PDYN (PDYN ${ }^{\mathrm{WT}}$ ) or SCA23-mutant PDYNR212W (PDYN $\left.{ }^{\mathrm{R} 212 \mathrm{~W}}\right)$ and examined whether mutant dynorphin A may impair motor performance and induce neuropathological changes similar to those in patients with SCA23.

\section{Materials and methods}

\section{Animals}

All animal experiments were performed according to the guidelines of the University of Groningen, The Netherlands, and the Mayo Clinic College of Medicine, Rochester, Minnesota, USA. The experimental protocols were approved by the Animal Welfare Committee of the University of Groningen. All efforts were made to reduce the number of animals and minimize their suffering. To generate transgenic mice expressing wild-type (WT) PDYN or SCA23-mutant PDYN-R212W under Cre-recombinase control, the PDYN cDNA was cloned into the pCALL2 plasmid downstream of a neomycin-resistance gene and transcription stop signal (three tandemly arranged polyadenylation sites) flanked by loxP sites (van Ree et al., 2010). Embryonic stem cell electroporation and clone selection was performed as described previously (van Ree et al., 2010; Baker et al., 2013). The blastocyst injections were performed at the Mayo Clinic College of Medicine. The genotypes were assessed by PCR using the following primers: PDYN-For 5'-TAGCAGTGGCG TTCATTTTG-3' and PDYN-Rev 5'-TCTGAGCTCCTCTTGG GGTA-3'; loxP-For 5'-TCACTGCATTCTAGTTGTGGT-3', and loxP-Rev 5'-CTTATCGATACCGTCGACCT-3'.

All mice used for the experiments had a mixed 129Sv/ $\mathrm{E} \times \mathrm{C} 57 \mathrm{Bl} / 6$ genetic background, and wild-type littermates were used as controls. Four independent cohorts $(n=10-12)$ of PDYN ${ }^{W T}$ and PDYN ${ }^{\mathrm{R} 212 \mathrm{~W}}$, and littermate controls were aged for 3, 6, 9 and 12 months. Each cohort contained equal numbers of male and female mice, and the mice were of the indicated age. In addition to PDYN, transgenic mice also ubiquitously express enhanced green fluorescent protein (EGFP). 


\section{Reverse transcription PCR and quantitative real-time PCR}

Total RNA was isolated from snap-frozen mouse cerebella using TRIzol ${ }^{\circledR}$ reagent (Life Technologies, Invitrogen). Complementary DNA was generated using oligo-d(T) primers and RevertAid ${ }^{\mathrm{TM}}$ cDNA Kit (Thermo-Scientific, Fermentas). Quantitative real-time expression analysis was performed using SYBR $^{\circledR}$ Green Mix (Life Technologies, Applied Biosystems) on the TaqMan ${ }^{\circledR}$ ABI7900HT PCR system (Life Technologies, Applied Biosystems) using the Standard Curve Quantification method and Gapdh and Ppia as reference genes. The list of primers used is given in Supplementary Table 1. All procedures were performed according to the manufacturers' protocols.

\section{Protein extraction and western blotting}

Proteins were isolated from snap-frozen mouse organs. Organs were homogenized in ice-cold isolation buffer $\left[1 \%\right.$ Triton $^{\text {TM }}$ $\mathrm{X}-100$ (Sigma) in $10 \mathrm{mM}$ Tris-HEPES, pH7.6] supplemented with a complete protease inhibitor cocktail (Roche) and $50 \mathrm{mM}$ dithiothreitol. Samples were centrifuged for $15 \mathrm{~min}$ at $10000 \mathrm{rpm}$, and protein concentrations were determined using the Pierce BCA Protein Assay Kit (Thermo Scientific), $2 \times$ Novex Tricine SDS sample buffer (Life Technologies) was added to the protein lysates and equal amounts were loaded on sodium dodecyl sulphate polyacrylamide gel electrophoresis (SDS-PAGE) gels. After electrophoresis, the proteins were transferred to polyvinylidene difluoride (PVDF) membrane (Life Technologies) and blocked with 5\% non-fat milk in Tris-buffered saline (TBS)-Tween. The blots were analysed with primary antibodies against human PDYN (rabbit, 1:500), dynorphin A (rabbit, 1:300, Abcam), vesicular glutamate transporter 2 (vGlut2; rabbit, 1:1000, Synaptic Systems), EAAT4 (rabbit, 1:500, Alpha Diagnostics) or Calbindin (mouse, 1:500, Abcam). Secondary antibodies were conjugated with horseradish peroxidase (goat, 1:10000, Jackson ImmunoResearch Laboratories). Densitometric analysis was performed using Fiji software (National Institutes of Health, USA, http://fiji.sc/). Protein bands were normalized against tubulin bands of the same sample.

\section{Radioimmunoassay}

The radioimmunoassay procedure was described elsewhere (Christensson-Nylander et al., 1985; Yakovleva et al., 2006). Briefly, tissue samples were extracted in $1 \mathrm{M}$ acetic acid, peptide fractions were isolated by SP Sephadex ${ }^{\circledR}$ ion exchange C-25 chromatography, and peptides were analysed by radioimmunoassay.

\section{Histology, immunofluorescent stain- ings, silver stainings and microscopy}

For immunofluorescent stainings, brains were dissected and fixed overnight in $15 \%$ picric acid, $4 \%$ paraformaldehyde and $0.05 \%$ glutaraldehyde in $0.1 \mathrm{M}$ phosphate buffer. After fixation, brains were cryopreserved in $10 \%$ and $20 \%$ sucrose solutions in phosphate buffer overnight, and then frozen on dry ice. Sectioning was performed on an HM550 Microm cryostat (Thermo Scientific). Cerebella were cut into eight series of $30-\mu \mathrm{m}$ thick coronal sections. All stainings were performed free floating. For overall morphology studies, sections were stained with $1 \%$ Toluidine Blue (Sigma-Aldrich) for 2 min, washed with water, and mounted in Faramount mounting medium (Dako). For fluorescent staining, sections were blocked with $3 \%$ normal donkey serum (Jackson ImmunoResearch Laboratories) for $30 \mathrm{~min}$, after which antigen retrieval was carried out in $10 \mathrm{mM}$ citric acid buffer $(\mathrm{pH} 6.0)$ at $90^{\circ} \mathrm{C}$ for $20 \mathrm{~min}$. Sections were washed in TBS, alternated with TBS with $1 \%$ Tween for permeabilization. Sections were incubated with primary antibody overnight at $4{ }^{\circ} \mathrm{C}$ and subsequently with secondary antibodies for $1 \mathrm{~h}$ at room temperature, followed by Sudan Black B incubation to eliminate autofluorescence and transgenic GFP fluorescence $(0.1 \%$ in $70 \%$ ethanol; Sigma-Aldrich) (Supplementary Fig. 1A-F), washing with phosphate buffer $+0.02 \%$ Tween, and mounting (BrightMount mounting medium). The primary antibodies used were: anti-human PDYN (rabbit, 1:300, Yakovleva et al., 2006) anti-dynorphin A (rabbit, 1:300, Abcam), anti-vGlut2 (rabbit, 1:1000, Synaptic Systems), anti-EAAT4 (rabbit, 1:500, Alpha Diagnostics) and anti-Calbindin (mouse, 1:500, Abcam). Secondary anti-rabbit antibodies were conjugated with Alexa Fluor ${ }^{\circledR} 488$ and anti-mouse antibodies with Cy3 (both: donkey, 1:250, Jackson ImmunoResearch Laboratories).

For silver stainings, brain samples were dehydrated with a graded ethanol series, followed by xylene and paraffination. Paraffin sections were cut at a thickness of $5 \mu \mathrm{m}$. After subsequent deparaffination and rehydration, the cerebellar slides were placed in a $20 \% \mathrm{AgNO}_{3}$ solution for $20 \mathrm{~min}$ at $60^{\circ} \mathrm{C}$. After rinsing in distilled water, the slides were placed in a solution of $10 \% \mathrm{AgNO}_{3}$ (to which ammonia was added until the precipitate was dissolved) $+1 \mathrm{ml}$ of $25 \%$ sodium carbonate solution. The solution was stirred while drops of $3.7 \%$ formalin were added until the slides stained golden brown. After being rinsed in distilled water, the slides were placed in $5 \%$ sodium thiosulphate solution for $2 \mathrm{~min}$. Then the slides were rinsed again, followed by dehydration, xylene, and mounting. These slides were evaluated for the formation of 'torpedoes' (indicating axonal damage of Purkinje cells) and 'empty baskets' (indicating complete loss of individual Purkinje cells).

Sections were imaged using an AxioObserver Z1 fluorescence microscope (Zeiss) and Leica TCS SP8 confocal microscope, and the images were analysed using the ImageScope (Aperio e-pathology solutions, http://www.aperio.com) and Fiji software (National Institutes of Health, http://fiji.sc/).

\section{Motor performance analyses}

Footprint patterns were analysed using a runway $(80 \mathrm{~cm} \times 10.5 \mathrm{~cm}$ wide) with white paper on the bottom. Mouse paws were painted with non-toxic, water-soluble ink (black for hind paws and magenta for front paws; Liquitex). Five consecutive strides were measured for each animal (Brooks and Dunnett, 2009). To assess motor performance the accelerating rotarod test was used $(3-\mathrm{cm}$ diameter rotating cylinder; IITC). The training session contained three runs at a stable $20 \mathrm{rpm}$ at Day 1 , followed by two training days 
(three runs per day) at accelerating speed (from 4 to $30 \mathrm{rpm}$ within $180 \mathrm{~s}$, running $600 \mathrm{~s}$ in total). The experiment was performed on Day 4, identical to the exercise on Days 2 and 3. The minimal interval time in between the runs was $15 \mathrm{~min}$ (Brooks and Dunnett, 2009). All tests were performed without genotype information and scored and analysed by two independent researchers.

\section{Cerebellar examinations: Purkinje cell count, molecular layer thickness and climbing fibre distribution}

Purkinje cells were counted and averaged over $100 \mu \mathrm{m}$ and the climbing fibre distribution was quantified by measuring the height of the vGlut2 staining in the molecular layer relative to the calbindin staining in the same region. The Purkinje cell length was measured as the distance from the top of Purkinje cell soma to the tip of Purkinje cell dendrite, and the climbing fibre distribution in the molecular layer was measured from the top of Purkinje cell soma to the tip of climbing fibre arbour. In addition, the molecular layer thickness was measured. For molecular layer thickness and climbing fibre distribution, at least 10 measurements per section were taken in specific cerebellar regions. One series of cerebellar sections per animal and two animals per genotype (controls, PDYN ${ }^{\mathrm{WT}}$ and $P D Y N^{\mathrm{R} 212 \mathrm{~W}}$ ) were used for one staining. Full cerebellar regions including cerebellar lobules II, III, IV/V, VI, IX and $\mathrm{X}$, the paramedian lobule, paraflocculus, flocculus and simplex and CrusI and CrusII ansiform lobules (Sim/Crus) were present in different sections and two to five sections were analysed per region.

\section{Cerebellar primary cultures}

Cerebella of postnatal Day 5 pups were dissected and were kept on ice in supplemented PBS $(0.3 \%$ bovine serum albumin and $0.6 \%$ glucose) after removal of the meninges. After trypsinization, cerebella were disaggregated in Dulbecco's modified Eagle medium supplemented with $10 \%$ foetal bovine serum (FBS), $0.25 \%$ penicillin/streptomycin and DNase I (Sigma-Aldrich), with a succession of pipettes, decreasing in size. Cells were then counted and $\sim 200000$ cells were seeded onto poly-D-lysine/laminin coated glass coverslips in 24-wells plates, in Neurobasal ${ }^{\circledR}$ medium (Life Technologies, Gibco), supplemented with $0.5 \%$ FBS, $0.25 \%$ glutamine, $0.25 \%$ penicillin/streptomycin, and B27 (Life Technologies, Gibco). After $24 \mathrm{~h}$ of culturing, inhibitor Ara-C (Sigma-Aldrich) was added to the culture medium to decrease glial cell growth. Neurons were cultured for 10 days before experiments were conducted.

\section{Immunocytochemistry}

Cerebellar neurons were fixed in $4 \%$ paraformaldehyde for $10 \mathrm{~min}$ and washed with PBS. Blocking and permeabilization was performed with 5\% normal donkey serum (Jackson ImmunoResearch Laboratories) and $0.1 \%$ Triton (Sigma-Aldrich) in PBS for $1 \mathrm{~h}$. Neurons were incubated with primary antibodies overnight at $4{ }^{\circ} \mathrm{C}$, and for $1 \mathrm{~h}$ with secondary antibodies at room temperature. All antibodies were diluted in blocking solution, and the primary antibodies used were anti-human PDYN (rabbit, 1:100; Yakovleva et al., 2006), anti-dynorphin A (rabbit, 1:100, Abcam) and anti- $\beta 3$ tubulin (mouse, 1:100, Santa Cruz Biotechnology). Secondary anti-rabbit antibodies were conjugated with Alexa Fluor ${ }^{\circledR} 488$ and anti-mouse antibodies with Cy3 (both: donkey, 1:250, Jackson ImmunoResearch Laboratories).

Neurons were imaged using a Leica TCS SP8 confocal microscope, and the images were analysed using Fiji software (National Institutes of Health, http://fiji.sc/).

\section{Electrophysiological recordings}

The cerebellar neurons cultured on the poly-D-lysine/laminincoated coverslips were placed in a measuring chamber attached to an Axioskop 2 FS microscope (Zeiss). Membrane currents and voltages were measured using an Axopatch $200 \mathrm{~B}$ amplifier (Axon Instruments), using the whole-cell patch clamp technique. Pipettes were pulled from borosilicate glass (Clarke) and were filled with a solution containing: $\mathrm{KCl} 140 \mathrm{mM}$, HEPES $10 \mathrm{mM}$, EGTA $10 \mathrm{mM}, \mathrm{MgCl}_{2} 1 \mathrm{mM}, \mathrm{CaCl}_{2} 1 \mathrm{mM}, \mathrm{Na}_{2} \mathrm{ATP}$ $2 \mathrm{mM}$ (280-290 mOsm). The bathing solution contained $\mathrm{NaCl}$ $140 \mathrm{mM}$, KCl $4 \mathrm{mM}$, glucose $10 \mathrm{mM}, \mathrm{CaCl}_{2} 2 \mathrm{mM}$, HEPES $1.2 \mathrm{mM}$ and $\mathrm{MgCl}_{2} 1 \mathrm{mM}$ (mOsm 330). The $\mathrm{pH}$ of all solutions was adjusted to 7.40 . When used with these solutions, the pipettes had initial resistances of 5-8 M $\Omega$. Membrane currents were recorded at room temperature $\left(20-22^{\circ} \mathrm{C}\right)$ with the amplifier in voltage clamp mode.

Currents were low-pass filtered at $5 \mathrm{kHz}$ and sampled at $50 \mathrm{kHz}$ using a Digidata 1320 AD converter (Axon Instruments). Pipette capacitance and whole cell resistance were compensated by $80-85 \%$. After measuring the membrane currents, the amplifier was switched to current clamp mode. Following measurement of the resting membrane potential, the membrane potential was set to $-50 \mathrm{mV}$ using steady injected current through the patch pipette. Input resistance was measured using small depolarizing current steps. The cell was activated with a $500 \mathrm{~ms}$ pulse of depolarizing current. Voltage clamp step protocols were generated and data was analysed using Pclamp software (Axon Instruments).

\section{Statistical analysis}

All data was normalized against 3-month control data and expressed as mean \pm standard error of the mean (SEM), unless stated otherwise. Two-way ANOVA was used to determine the significance of the observed differences between the genotypes, and over time, unless stated otherwise $(P<0.05$ is considered statistically significant).

\section{Results}

\section{Expression of SCA23-mutant PDYN- R2I 2 W leads to elevated levels of cerebellar mutant dynorphin A}

Previous studies have shown that the SCA23 mutation, R212W, has the strongest effects on dynorphin A levels in cell models compared to other mutations (Bakalkin et al., 2010). In addition, R212W induces the strongest 
A

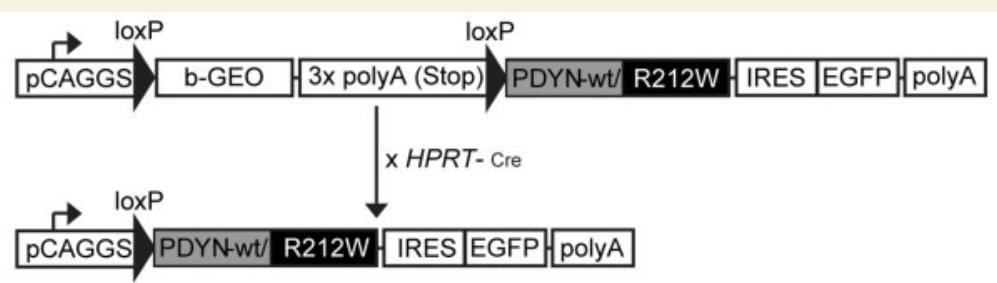

B

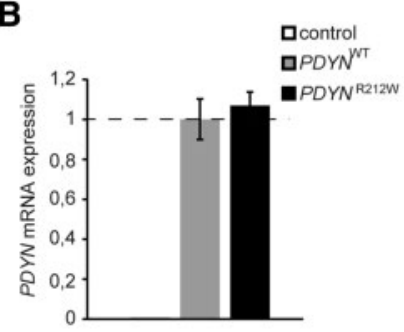

E

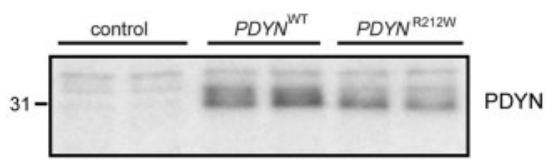

C

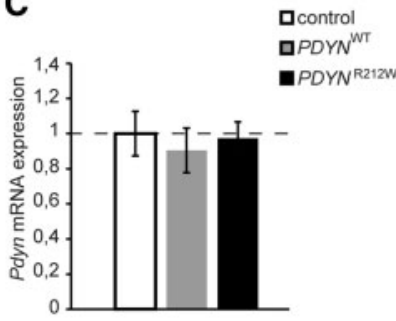

$\mathbf{F}$

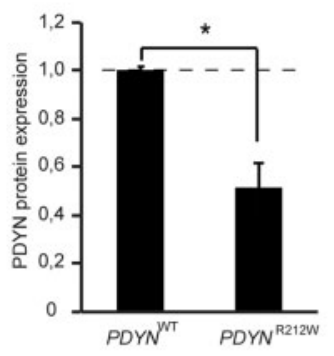

D

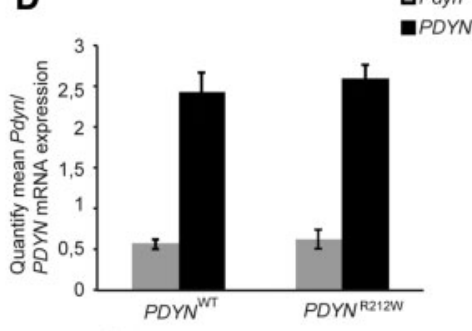

G

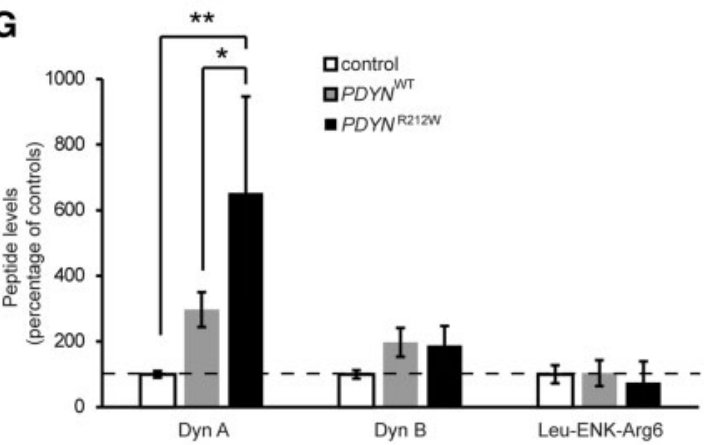

Figure I PDYN-R2I 2W expression leads to elevated mutant dynorphin A levels in the cerebellum of PDYN ${ }^{R 212 W}$ mice. (A) The transgene cassette contained the full PDYN cDNA downstream of two loxP sites flanking a transcription STOP signal of three consecutively arranged polyadenylation sites. (PDYN $\left.{ }^{W T}\right)^{\text {flox/flox }}$ and $\left(P^{2} \mathrm{PYN}^{\mathrm{R} 212 \mathrm{~W}}\right)^{\text {flox/flox }}$ mice are crossed with HPRT-cre mice to ubiquitously express the PDYN transgene. (B) PDYN mRNA expression levels in the cerebella of 3-month-old PDYN ${ }^{\mathrm{WT}}$, PDYN $\mathrm{R}^{\mathrm{R} 2 \mathrm{I} 2 \mathrm{~W}}$ and littermate control mice (control), normalized against 3 -month-old PDYN ${ }^{W T}$ mice revealed by real-time PCR $\left(n=6\right.$, per genotype). PDYN ${ }^{W T}$ and $P D Y N^{R 212 W}$ mice showed equal transgene expression. Values are mean \pm SEM. (C) Endogenous Pdyn mRNA levels in the cerebella of 3-month-old PDYN ${ }^{W T}, P D Y N^{R 2 I 2 W}$ and control mice, normalized against 3-month-old control mice revealed by real-time PCR ( $n=6$, per genotype). Expression of PDYN-wt and PDYNR2 I2W did not influence Pdyn mRNA levels. Values are mean \pm SEM. (D) The quantity mean Pdyn and PDYN mRNA expression. Both PDYN ${ }^{W T}$ and $P D Y N^{R 212 W}$ mice showed \pm 5 -fold increase in total PDYN/Pdyn mRNA expression. Values are mean \pm SEM. (E) Representative immunoblot image of PDYN protein levels in cerebella of PDYN ${ }^{\mathrm{WT}}$, PDYN ${ }^{\mathrm{R} 212 \mathrm{~W}}$ and littermate controls at 3 months of age, stained with anti-C-terminal human PDYN antibody. For full-length immunoblot see Supplementary Fig. 3. (F) Quantification of PDYN protein levels in 3-month-old mice. Results were normalized using MemCode staining. PDYN ${ }^{R 212 W}$ mice showed \pm 1.3 -fold decreased PDYN protein levels compared to PDYN ${ }^{W T}$ mice. $* P<0.05$, $* * P<0.01$. (G) Relative dynorphin A (Dyn A), dynorphin B (DYN B), and Leu-ENK-Arg ${ }^{6}$ peptide levels in 3-month-old cerebella $(n=2$, per genotype) determined by radioimmunoassay. PDYN ${ }^{W T}$ mice showed a \pm 3.9 -fold and \pm 2.4 -fold increase in dynorphin $A$ and dynorphin $B$ peptide levels compared to littermate controls, respectively. Additionally, $P D Y N^{R 212 W}$ mice showed a $\pm \mathrm{I}$ I. I- and \pm 2.8 -fold increase in dynorphin $A$ and dynorphin $B$ peptide levels compared to littermate controls, respectively. Notably, a \pm 2.8 -fold increase in dynorphin $A$ peptide levels were observed in PDYN ${ }^{R 212 W}$ mice compared to age-matched PDYN ${ }^{W T}$ mice. Values are expressed as the percentage of control mice. $* P<0.05$, ${ }^{* * P}<0.01$.

non-opioid nociceptive activity upon injection of dynorphin A into mice (Watanabe et al., 2012). To examine the causal role of mutant PDYN-R212W in the pathology of SCA23, we ubiquitously expressed PDYN-wt or PDYN-R212W by crossing $\left(P D Y N^{\mathrm{WT}}\right)^{f l o x} / f l o x$ and $\left(P D Y N^{\mathrm{R} 212 \mathrm{~W}}\right)^{f l o x} /$ flox mice with hypoxanthine-guanine phosphoribosyl transferaseCre (HPRT-Cre) mice (Nichol et al., 2011) (Fig. 1A).

Heterozygous $P D Y N^{\mathrm{WT}}$ and $P D Y N^{\mathrm{R} 212 \mathrm{~W}}$ mice were born at the expected Mendelian frequency, were fertile, appeared healthy, and displayed body weight that was indistinguishable from control littermates (data not shown). Transgenic
PDYN mRNA expression was equally high in the cerebella of $P D Y N^{\mathrm{WT}}$ and $P D Y N^{\mathrm{R} 212 \mathrm{~W}}$ mice at 3 months of age (Fig. $1 \mathrm{~B})$, which significantly decreased in $P D Y N^{\mathrm{WT}}$ mice but not in $P D Y N^{\mathrm{R} 212 \mathrm{~W}}$ mice at 12 months of age (Supplementary Fig. 2A). Transgenic PDYN wild-type or R212W expression did not affect endogenous $P d y n$ mRNA expression at 3 months of age (Fig. 1C), whereas clearly reduced Pdyn expression was observed in $P D Y N^{\mathrm{R} 212 \mathrm{~W}}$ mice at 12 months of age (Supplementary Fig. 2B). This led to approximately equal PDYN/Pdyn mRNA levels in both models at 3 and 12 months of age. Both PDYN ${ }^{\mathrm{WT}}$ and $P D Y N^{\mathrm{R} 212 \mathrm{~W}}$ mice 
showed $\sim 5$-fold elevated PDYN/Pdyn mRNA levels compared to control mice (Fig. 1D). Despite the equal PDYN/Pdyn mRNA levels at 3 and 12 months of age, significantly lower PDYN protein levels were observed in PDYN ${ }^{\mathrm{R} 212 \mathrm{~W}}$ cerebella compared to PDYN ${ }^{\mathrm{WT}}$ at age 3 and 12 months of age (Fig. 1E, Supplementary Figs 2D and 3). Consistent with lower PDYN protein levels in cerebellum, PDYN protein levels were reduced in brain, kidney and liver of $P D Y N^{\mathrm{R} 212 \mathrm{~W}}$ mice (Supplementary Figs 2C-H and 4). These results suggest that PDYN-R212W is either more efficiently processed into peptides or is more rapidly degraded than PDYN-wt.

To examine the processing of PDYN-wt and PDYNR212W to dynorphin A, dynorphin B and conversion to Arg-Leu-enkephalin (Leu-ENK-Arg ${ }^{6}$ ), the cerebella of $P D Y N^{\mathrm{WT}}, P D Y N^{\mathrm{R} 212 \mathrm{~W}}$ mice and their age-matched controls were analysed by radioimmunoassay. We observed that PDYN expression resulted in marked increased levels of dynorphin $\mathrm{A}$ and dynorphin $\mathrm{B}$ in the cerebella of $P_{D Y N}{ }^{\mathrm{WT}}$ and $P D Y N^{\mathrm{R} 212 \mathrm{~W}}$ mice, compared to littermate controls at 3 and 12 months of age (Fig. 1G and Supplementary Fig. 2K). Especially, significantly increased dynorphin A levels in $P D Y N^{\mathrm{R} 212 \mathrm{~W}}$ mice were observed compared to $P D Y N^{\mathrm{WT}}$ mice at both 3 and 12 months of age. This effect was not observed for dynorphin B and Leu-ENK$\mathrm{Arg}^{6}$ peptide levels, suggesting that the R212W mutation selectively alters the processing of PDYN to dynorphin A.

Consistent with clear cerebellar PDYN protein expression on western blot, strong and specific PDYN and dynorphin A immunofluorescence signals (in purple) were detected in the molecular, Purkinje cell and granule cell layers of $P D Y N^{\mathrm{WT}}$ and $P D Y N^{\mathrm{R} 212 \mathrm{~W}}$ mice at both age 3 and 12 months (Fig. 2 and Supplementary Fig. 3). These signals were also observed in the Purkinje cell soma as was shown by co-localization with the Purkinje cell-specific marker calbindin (in green), indicating that Purkinje cells express PDYN and dynorphin A. In general, dynorphin A localized more to the molecular layer (Fig. $2 \mathrm{Q}$ and $\mathrm{R}$ ) than PDYN, which showed a more focal localization in the Purkinje cell soma (Fig. 2H and I).

Taken together, these results show that both transgenic mouse lines have robust expression of PDYN-wt or PDYNR212W in the cerebellum. Despite the low precursor levels, $P D \mathrm{~N}^{\mathrm{R} 212 \mathrm{~W}}$ mice showed highly elevated ( 2-3-fold) cerebellar mutant dynorphin A levels compared to PDYN ${ }^{\mathrm{WT}}$ mice. These results are in line with our previous data that showed that the PDYN R212W mutation led to significantly enhanced dynorphin A peptide levels in cell models (Bakalkin et al., 2010), which is likely to be a direct consequence of enhanced PDYN-R212W processing.

\section{Expression of PDYN-R2 I 2W causes Purkinje cell death and loss of climb- ing fibre-Purkinje cell innervation}

To investigate whether PDYN-wt or PDYN-R212W expression causes cerebellar pathology, we performed a toluidine blue staining to study the gross morphology of the cerebellum. The cerebella of both $P D Y N^{\mathrm{WT}}$ and $P D Y N^{\mathrm{R} 212 \mathrm{~W}}$ mice did not show any major abnormalities and were of similar size as littermate controls at 3 and 12 months of age, including the molecular layer (Supplementary Fig. 4A-G). However, lobule II did show significant thinning in 12-month-old PDYN ${ }^{\mathrm{R} 212 \mathrm{~W}}$ mice (Supplementary Fig. 4G) and a more detailed analysis revealed significantly marked Purkinje cell loss in the vermal lobules II, III, VI and in the hemispheric regions Sim/Crus of 12 -month-old PDYN ${ }^{\mathrm{R} 12 \mathrm{~W}}$ mice compared to both PDYN ${ }^{\mathrm{WT}}$ mice and littermate controls (Fig. 3A). This was not observed at 3 months of age (data not shown). The age-dependent Purkinje cell pathology was confirmed by calbindin immunostainings and Sevier-Munger stainings. Purkinje cells of 12-month-old PDYN ${ }^{\mathrm{R} 212 \mathrm{~W}}$ mice showed mild atrophy of the dendritic tree and loss of Calbindin staining (Fig. 3B-D). Additionally, Sevier-Munger stainings demonstrated several stages of Purkinje cell damage in $P D Y N^{\mathrm{R} 212 \mathrm{~W}}$ mice, including rare axonal torpedoes (Fig. 3E), single and multiple empty baskets (Fig. 3F and G), and chronic Purkinje cell loss indicated by the absence of normal Purkinje cell layer structure (Purkinje cells and basket cells) (Fig. $3 \mathrm{H}$ ). In contrast, age-matched PDYN ${ }^{\mathrm{WT}}$ and littermate control cerebella only very rarely displayed a single empty basket, which was most likely the result of normal ageing (data not shown). Larger stretches with empty baskets or areas with chronic Purkinje cell loss were never observed. No Purkinje cell layer pathology was observed in 3-month-old $P D Y N^{\mathrm{R} 212 \mathrm{~W}}$ mice (data not shown), suggesting degeneration occurs relatively late and progresses slowly, mirroring the human disease (Verbeek et al., 2004).

Next, we analysed the Purkinje cell pathology more precisely by examining climbing fibre-Purkinje cell synapses, using vGlut2 as a marker (Fremeau et al., 2001). Altered distribution of climbing fibre synapses was previously seen in SCA1 and SCA7 mice (Duvick et al., 2010; Furrer et al., 2013), reflected by reduced vGlut $2 /$ calbindin ratios along the Purkinje cell dendrites. The Purkinje cell dendrites of $P D Y N^{\mathrm{R} 212 \mathrm{~W}}$ mice showed a significantly reduced climbing fibre synapse distribution in the vermal lobules II, VI and IX, and in the paraflocculus compared to PDYN ${ }^{\mathrm{R} 212 \mathrm{~W}}$ mice and littermate controls, respectively (Fig. 4A and B). These effects were also observed in lobules II, VI, IX, and paraflocculus of 3-month-old $P D Y N^{\mathrm{R} 212 \mathrm{~W}}$ mice which significantly progressed over time up to 12 months of age (Fig. 4B). This suggests that expression of PDYN-R212W caused early changes in the climbing fibre-Purkinje cell synapses, and that these changes progress with age and lead to Purkinje cell degeneration over time. Notably, the loss of climbing fibre-Purkinje cell synapses is mostly restricted to the anterior vermis and lobule VI; regions found to be responsible for motor coordination and balance (Manni and Petrosini, 2004; Stoodley and Schmahmann, 2010). 

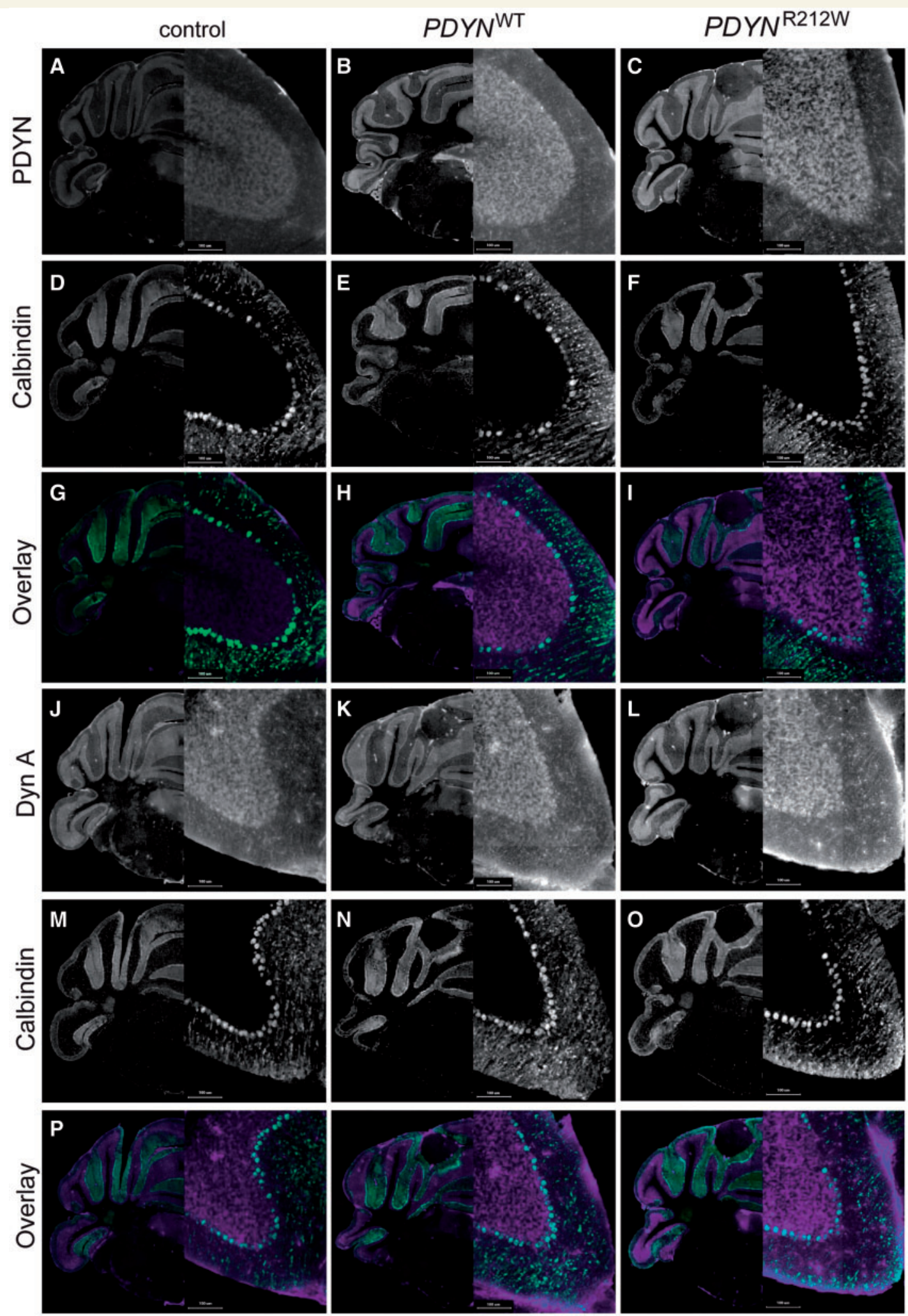

Figure 2 PDYN and dynorphin A expression in cerebellar Purkinje cells of PDYNWT and PDYN ${ }^{\mathrm{R} 212 \mathrm{~W}}$ mice. Representative immunofluorescence images of PDYN (A-I, purple) and dynorphin A (Dyn A, J-R, green) in cerebella of 3-month-old control, PDYN ${ }^{W T}$ and $P D Y N^{R 212 W}$ mice. The Purkinje cell-specific marker calbindin (in green) was used to identify the Purkinje cell soma and dendrites (D-F and $\mathbf{M}-\mathbf{O}$, for PDYN and dynorphin A, respectively) and the overlay (G-I and P-R, for PDYN and dynorphin A, respectively). Both PDYN ${ }^{W T}$ and PDYN ${ }^{R 2 I 2 W}$ mice showed marked PDYN expression throughout the cerebellum. PDYN expression shows clear co-localization with the Purkinje cell soma, whereas dynorphin A expression was mainly detected in the molecular layer, and to a lesser extend in the Purkinje cells. No clear difference was observed in the PDYN and dynorphin A immunofluorescence between PDYN ${ }^{W T}$ and PDYN $212 \mathrm{~W}$ mice. Micrographs of cerebellar overall morphology and $\times 20$ magnification. Scale bar $=100 \mu \mathrm{m}$. 

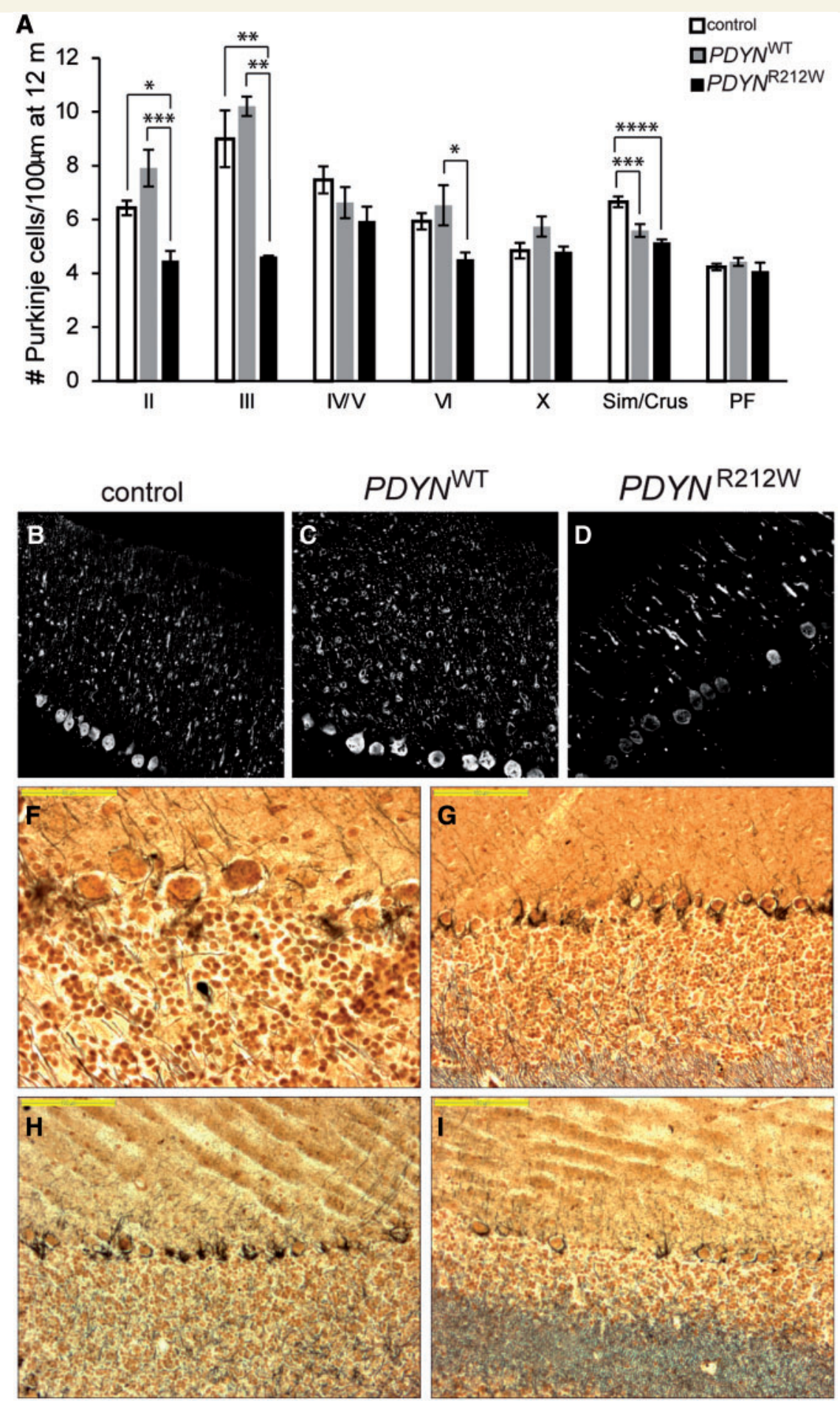

Figure 3 Loss and atrophy of Purkinje cells in PDYN ${ }^{\mathrm{R} 2 \mathrm{I} W \mathrm{~W}}$ mice at 12 months of age. (A) Purkinje cells count in the vermal lobules II, III, IV/V, VI, X, and Sim/Crus, and paraflocculus (PF) in toluidine blue sections of the cerebellum of I2-month-old PDYN ${ }^{W T}$ and PDYN ${ }^{R 2 I 2 W}$ mice $\left(n=5-7\right.$, per genotype). PDYN ${ }^{R 2 I 2 W}$ mice showed significantly less Purkinje cells in the vermal lobules II, III, and VI, and Sim/Crus compared to PDYN ${ }^{W T}$ and control mice. PDYN ${ }^{R 212 W}$ mice showed on average $4.5 \pm 0.36,4.6 \pm 0.04,4.52 \pm 0.26$ Purkinje cells per $100 \mu \mathrm{m}$ in the vermal lobules II, III, and VI, and 5.I \pm 0.22 in Sim/Crus compared to $7.4 \pm 0.52,10.2 \pm 0.36,6.53 \pm 0.75$, and $5.59 \pm 0.27$ Purkinje cells per I00 $\mu \mathrm{m}$ in PDYN ${ }^{W T}$ mice. Data are presented as mean \pm SEM. ${ }^{* P}<0.05$, $* * P<0.01$, $* * * P<0.00$ I, and $* * * * P<0.000$ I. (B-D) Representative calbindin immunofluorescence images from affected vermal regions of the Purkinje cell and molecular layers of cerebellar from I2-month-old control, PDYN ${ }^{W T}$ and PDYN ${ }^{R 212 W}$ mice. PDYN ${ }^{R 212 W}$ mice showed reduced calbindin immunofluorescence and mild dendritic atrophy compared to PDYN ${ }^{W T}$ and control mice. Scale bar $=100 \mu \mathrm{m}$. (E-H) Representative micrographs of Silver-Munger stainings of the Purkinje cell and molecular layer of 12-month-old PDYN ${ }^{R 212 W}$ mice. The Purkinje cell layer of PDYN ${ }^{R 212 W}$ mice showed torpedoes $(\mathbf{E})$, empty baskets (F-H), and regions without empty baskets $(\mathbf{G})$. This pathology was not observed in age-matched PDYN ${ }^{W T}$ and control mice $(n=2-3$, per genotype). Scale bars in $\mathbf{E}=50 \mu \mathrm{m}$, $\mathbf{F}-\mathbf{H}=100 \mu \mathrm{m}$. 
A 3 months

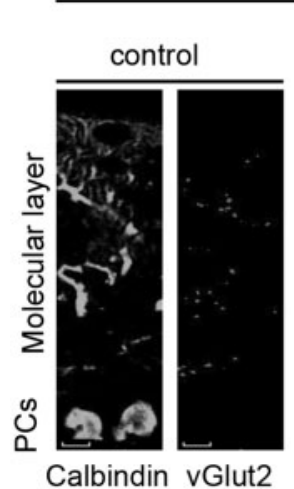

Calbindin vGlut2

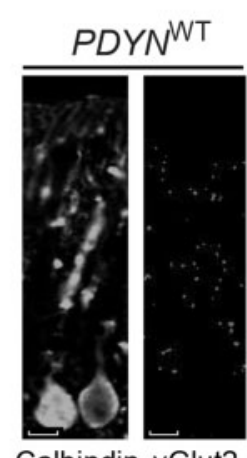

Calbindin vGlut2

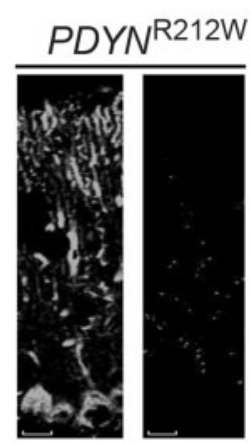

Calbindin vGlut2

\section{2 months}

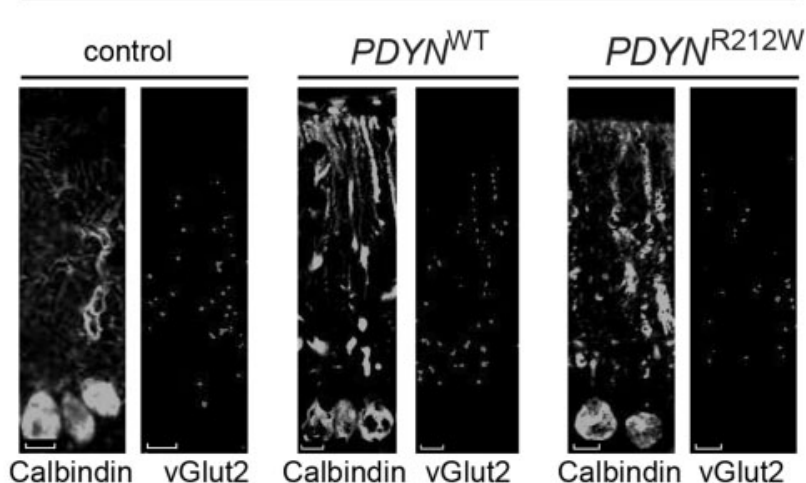

B 口control $\square P D Y N^{N T} \square P D Y N^{R 212 W}$

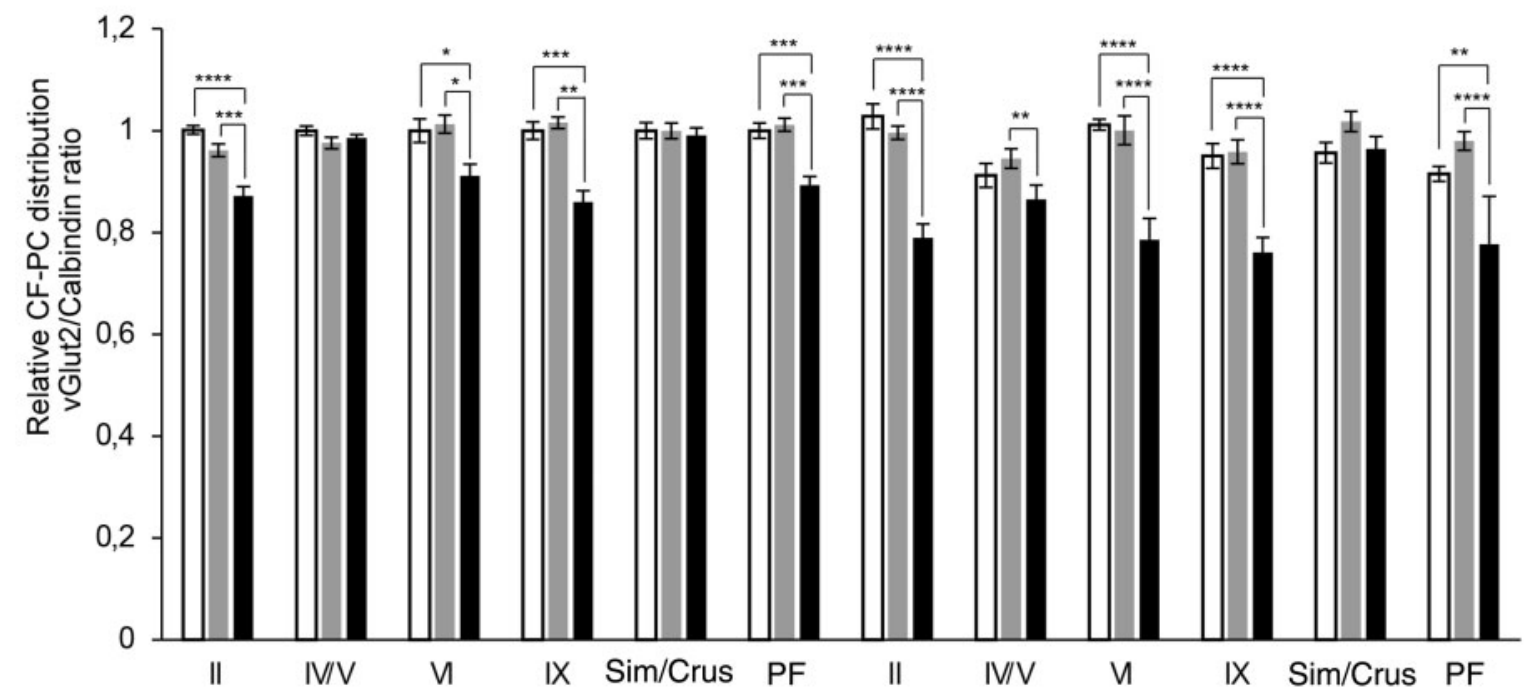

3 months

12 months

Figure 4 Reduced climbing fibre synapses at Purkinje cell dendrites in PDYN ${ }^{\text {R212W }}$ mice. The distribution of climbing fibres (CF) and Purkinje cell (PC) dendritic tree in the vermal lobules II, IV/V, VI, IX, and Sim/Crus, and paraflocculus (PF) was assessed by vGlut2 and calbindin immunostaining, respectively. (A) Representative confocal images of lobule $\mathrm{VI}$ of the cerebella of control, PDYN ${ }^{\mathrm{WT}}$ and PDYN ${ }^{\mathrm{R} 2 \mathrm{I} 2 \mathrm{~W}}$ mice at 3 and 12 months of age stained with anti-calbindin antibody, and anti-vGlut2 antibody. Three- and I2-month-old control, PDYN ${ }^{W T}$ and PDYN ${ }^{R 2 I 2 W}$ mice showed a mean relative height of climbing fibre to molecular layer thickness of $0.78 \pm 0.02,0.79 \pm 0.01,0.71 \pm 0.02$, and $0.79 \pm 0.01$,

$0.78 \pm 0.02$, and $0.62 \pm 0.03$, respectively. (B) Quantification of the relative height of vGlut2 staining compared to molecular layer thickness, represented by calbindin staining, in the lobules II, IV/V,VI, IX, Sim/Crus and parallel fibre in control, PDYN ${ }^{W T}$ and PDYN ${ }^{R 2 I 2 W}$ mice of 3 and I2 months of age ( $n=5-7$, per genotype). At 3 months of age, $P D Y N^{R 212 W}$ mice already showed significantly reduced climbing fibre-Purkinje cell synapses in lobules II, VI, IX, and parallel fibre compared to PDYN ${ }^{\mathrm{WT}}$ and control mice. In these regions, $P D Y N^{\mathrm{R} 212 \mathrm{~W}}$ mice showed a relative height of vGlut2 staining compared to molecular layer thickness of $0.7 \mathrm{I} \pm 0.02,0.72 \pm 0.02,0.60 \pm 0.02$, and $0.62 \pm 0.07$ compared to $0.8 \mathrm{I} \pm 0.0 \mathrm{I}$, $0.78 \pm 0.02,0.76 \pm 0.02$, and $0.78 \pm 0.02$ in age-matched PDYN ${ }^{W T}$ mice. This effect significantly progressed over time in the vermal lobules II $(0.64 \pm 0.02, P=0.006), \mathrm{VI}(0.72 \pm 0.02, P<0.000 \mathrm{I})$, and $\mathrm{IX}(0.60 \pm 0.02, P=0.0173)$ in $P D Y N^{R 2 I 2 W}$ mice but not for the parallel fibre. Data are normalized to 3 -month-old controls and presented as mean \pm SEM. $* P<0.05$, $* * P<0.0$ I, $* * * P<0.00 \mathrm{I}$, and $* * * * P<0.000 \mathrm{I}$.

\section{PDYN $^{\mathrm{R2} \text { I2W }}$ mice exhibit gait deficits and motor dysfunction revealing cerebellar ataxia}

To test whether the subtle but significant and progressive morphological alterations observed above translate into neurological effects, we assessed gait- and motor performance over time using footprint pattern analysis and the accelerating rod test. Footprint patterns were analysed for differences in hind base width and the overlap of steps between the front and hind paws, which are characteristic for ataxia (Manto and Marmolino, 2009). The hind base 
width of $P D Y N^{\mathrm{R} 212 \mathrm{~W}}$ mice was significantly wider than $P D Y N^{\mathrm{WT}}$ mice at all ages, and significantly wider than control mice at 3, 6 and 9 months of age (Fig. 5A). Already at 3 months of age, $P D Y N^{\mathrm{R} 212 \mathrm{~W}}$ mice also showed significant loss of step overlap in contrast to $P D Y N^{\mathrm{WT}}$ and control mice, which progressively reached maximal loss of step overlap at 9-12 months of age (Fig. $5 \mathrm{~B})$. The performance on the accelerating rod was only significantly diminished in $P D Y N^{\mathrm{R} 212 \mathrm{~W}}$ mice at 12 months of age compared to littermate controls, as their time on the rod was markedly reduced (Fig. 5C). Although 12-month-old $P D Y N^{\mathrm{R} 212 \mathrm{~W}}$ mice performed worse than age-matched $P D Y N^{\mathrm{WT}}$ mice, this difference was not significant.

Altogether, these data show that $P D Y N^{\mathrm{R} 212 \mathrm{~W}}$ mice exhibit a mild, slowly progressive, impairment of motor coordination with deficits in balance and step alterations, reflecting the mild and progressive neurological symptoms of SCA23 patients.

\section{PDYN $^{\text {R2I2W }}$ mice show altered expression of opioid and glutamatergic signalling}

To address the consequence of the elevated mutant dynorphin A peptide levels on opioid signalling, we studied the mRNA expression levels of the opioid receptors Oprd1, Oprk1, and Oprm1. The expression of PDYN-wt and PDYN-R212W did not affect Oprd1, Oprk1 and Oprm1 mRNA levels in cerebellum at 3 months of age (Fig. 6A), but at 12 months of age, $P D Y N^{\mathrm{WT}}$ mice and control mice showed significantly increased Oprk1 and Oprm1 mRNA expression levels compared to PDYN ${ }^{\mathrm{R} 212 \mathrm{~W}}$ mice (Fig. 6A). Notably, this increase in receptor expression was also significant over time for the control mice but not for PDYN ${ }^{\mathrm{WT}}$ mice. Thus, PDYN-R212W reduced opioid receptor expression in the cerebellum at 12 months of age.

We hypothesized that the abundant mutant dynorphin A peptides switch to another receptor system as has been described for elevated wild type dynorphin A levels in a pain model (Lai et al., 2006). Therefore, we next studied the mRNA expression levels of components of the glutamatergic system over time in cerebellum, including the NMDA-R subunits Grin1, Grin2a, and Grin $2 b$, the AMPA-R subunits Gria2 and Gria3, as dynorphin A-induced cell death in cell models was previously shown to be mediated via both NMDA-Rs (Tan-No et al., 2001) and AMPA-Rs (Singh et al., 2003). No significant differences were detected for Grin1 and Grin $2 b$ mRNA levels between the different genotypes and time points. However, a significant increase in Grin $2 a$ expression was observed in 3-month-old PDYN ${ }^{\mathrm{R} 212 \mathrm{~W}}$ mice compared to $P D Y N^{\mathrm{WT}}$ and littermate controls, but not at 12 months of age (Fig. 6B). Gria2 and Gria3 mRNA levels were identical for all genotypes at age 3 months, but the trend in age-dependent decline (not significant) in Gria2 and Gria3 expression in controls and PDYN ${ }^{\mathrm{WT}}$ mice was significantly prevented in $P D Y N^{\mathrm{R} 212 \mathrm{~W}}$ mice (Fig. 6C). We lastly examined the expression of glutamate transporters Slc1a3, Slc1a1 and Slc1a6. At 3 months, only Slc1a1 mRNA levels were significantly elevated in $P D Y N^{\mathrm{R} 212 \mathrm{~W}}$ mice compared to control mice (Fig. 6D). Whereas a significant increase in Slc1a3 expression was seen in 12-monthold $P D Y N^{\mathrm{R} 212 \mathrm{~W}}$ mice compared to $P D Y N^{\mathrm{WT}}$ mice and littermate controls (Fig. 6D). These changes in the mRNA levels of components of the glutamatergic system imply that expression of PDYN-R212W affects the glutamate system.

Overall, these results indicate that the elevated mutant dynorphin A levels likely add to disturbed opioid and glutamatergic signalling in the cerebellum and subsequently contributes to SCA pathogenesis.

\section{Increased expression of PDYN- R2 I 2 W causes electrophysiological changes in cultured cerebellar neurons}

To determine whether expression of PDYN-R212W causes altered neuronal excitability in the cerebellum, we performed electrophysiological experiments on cultured cerebellar neurons from P5 control, PDYN ${ }^{\mathrm{WT}}$ and PDYN ${ }^{\mathrm{R} 212 \mathrm{~W}}$ pups. As shown in Supplementary Fig. 7, PDYN ${ }^{\mathrm{WT}}$ and $P D Y N^{\mathrm{R} 212 \mathrm{~W}}$ cultures expressed PDYN at similar levels (Supplementary Fig. 7E-L), whereas control cultures only showed background staining (Supplementary Fig. 7A-D). All cultures expressed dynorphin A, with the lowest levels in control neurons and the highest levels in $P D Y N^{\mathrm{R} 212 \mathrm{~W}}$ neurons (Supplementary Fig. $7 \mathrm{M}-\mathrm{X}$ ), similar to mice at 3 and 12 months of age. No significant morphological differences were observed between the genotypes (data not shown). The cultured neurons were analysed at 10 days in vitro by whole cell patching, and whole cell currents were compared. We showed that $P D Y N^{\mathrm{R} 212 \mathrm{~W}}$ cerebellar neurons exhibit similar expression of voltage-dependent membrane currents (IV curve) compared to PDYN ${ }^{\mathrm{WT}}$ cerebellar neurons (Fig. 7A). Additionally, both PDYN ${ }^{\mathrm{WT}}$ and $P D Y N^{\mathrm{R} 212 \mathrm{~W}}$ cerebellar neurons showed significantly smaller $\mathrm{Na}^{+}$and $\mathrm{K}^{+}$currents than cerebellar neurons from control littermates. This suggests that overexpression of PDYN already has an effect on the physiological functioning of the cell.

Current clamp recordings showed that control cerebellar neurons were characterized by fast spike action potentials with an amplitude of $61.8 \pm 3.1 \mathrm{mV}$ and a half-width of $2.6 \pm 0.3 \mathrm{~ms}$ (Fig. 7B). PDYN ${ }^{\mathrm{WT}}$ neurons displayed typical granule cell action potentials (Huang et al., 1993) with a fast spike amplitude of $66.9 \pm 3.1 \mathrm{mV}$ and a half-width of $2 \pm 0.1 \mathrm{~ms}$ (Fig. $7 \mathrm{C}$ ). The activity in $P D Y \mathrm{~N}^{\mathrm{R} 212 \mathrm{~W}}$ cerebellar neurons was different from the other genotypes, in that the amplitude of the spikelets was much smaller, 
A
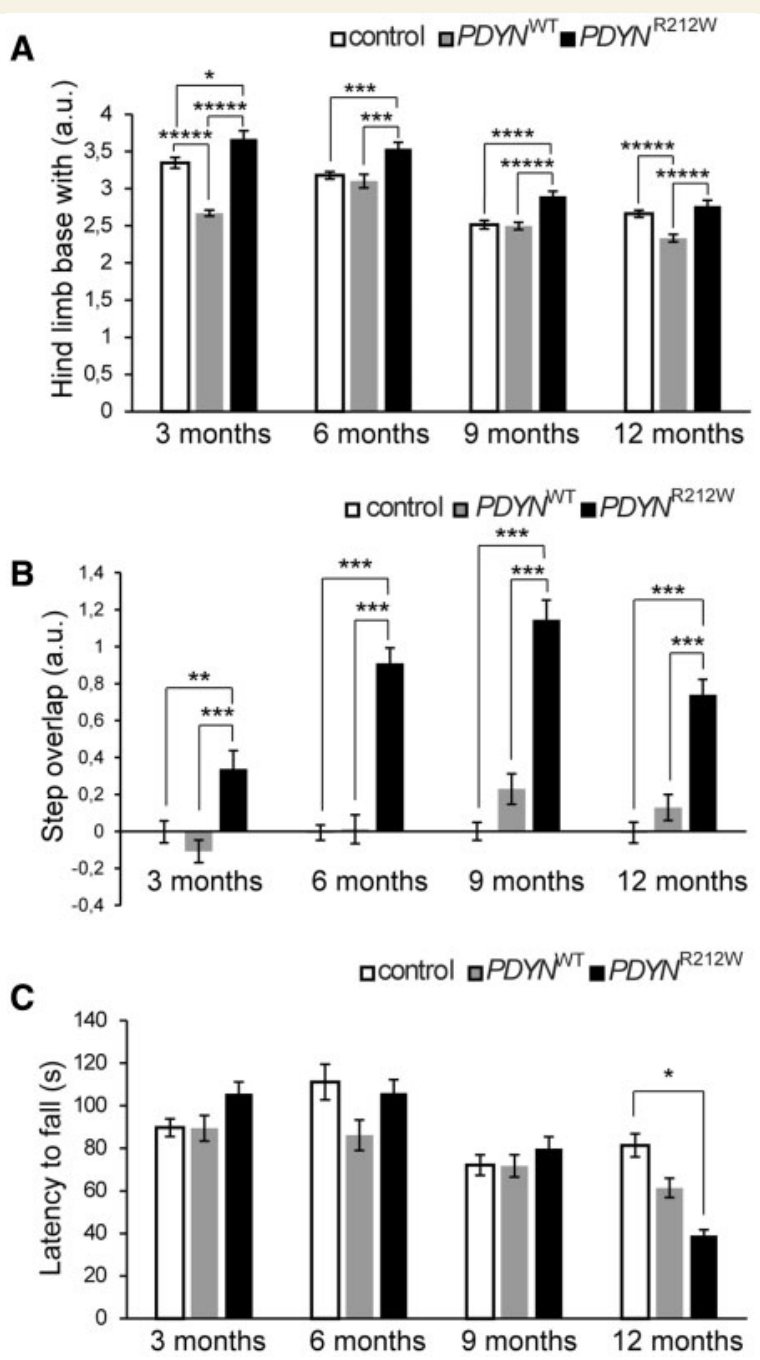

Figure 5 PDYN $^{\mathrm{R212W}}$ mice exhibit gait abnormalities and motor dysfunction. (A) Foot print pattern analysis of hind limb base with in control, PDYN ${ }^{\mathrm{WT}}$ and PDYN ${ }^{\mathrm{R} 2 \mathrm{I} W \mathrm{~W}}$ mice at $3,6,9$ and 12 months of age ( $n=6$, per transgenic line and $n=12$ for controls). $P D Y N^{R 212 W}$ mice showed a significantly wider hind limb base $(3.67 \pm 0.1 \mathrm{I})$ than $P D Y N^{\mathrm{WT}}(2.67 \pm 0.04)$ and control mice $(3.35 \pm 0.07)$ at 3 months of age. This effect persisted up to 12 months of age, where PDYN ${ }^{\mathrm{R} 212 \mathrm{~W}}$ mice showed a hind limb base with of $2.77 \pm 0.08$ compared to $2.33 \pm 0.05$ and $2.66 \pm 0.05$ in age-matched $P D Y N^{W T}$ and control mice, respectively. Students $t$-test, $* P<0.05$, and $* * * P<0.001$, $* * * * P<0.0001$, and $* * * * * P<0.00001$. (B) Foot print pattern analysis of the overlap of front and hind paw footprints in control, PDYN ${ }^{W T}$ and PDYN ${ }^{\mathrm{R} 212 \mathrm{~W}}$ mice at $3,6,9$, and 12 months of age ( $n=6$, per transgenic line and $n=12$ for controls). Perfect step overlap equals a score of 0 . Significant loss of step overlap in PDYN ${ }^{R 212 W}$ mice $(0.33 \pm 0.1)$ was observed starting at 3 months of age compared to PDYN ${ }^{W T}(-0.11 \pm 0.06)$ and control mice $(0 \pm 0.06)$. This deficit progressed with aging up to 9 months of age (range $0.33-1.15 \pm 0.10$ ). Loss of step overlap was not observed in PDYN ${ }^{W T}$ mice or littermate controls. One-way ANOVA, $* * P<0.01$, and $* * * P<0.001$ (C) Quantification of the latency to fall from the accelerating rotarod performance on experimental Day 4 of control, PDYN ${ }^{\mathrm{WT}}$ and PDYN ${ }^{\mathrm{R} 212 \mathrm{~W}}$ mice at 3, 6, 9, and 12 months of age $(n=6$, per transgenic line and $n=12$ for controls). Only at 12 months of age PDYN ${ }^{\mathrm{R} 212 \mathrm{~W}}$ mice showed a significantly decreased latency to fall compared with similarly aged
$37.2 \pm 2.4 \mathrm{mV}$ (Fig. 7D), and the membrane did not reach $0 \mathrm{mV}$. Furthermore, these spikelets had a half-width of $9.7 \pm 1.1 \mathrm{~ms}$ (Fig. 7D). Additionally, $P D Y N^{\mathrm{R} 212 \mathrm{~W}}$ cerebellar neurons displayed another action potential waveform, which can be described as a small excitatory post synaptic potential that did not progress into an action potential (Fig. 7E). Taken together, these results suggest that increased expression of PDYN impairs cell functioning leading to reduced $\mathrm{Na}^{+}$and $\mathrm{K}^{+}$currents. Furthermore, expression of PDYN-R212W causes a significant change in the action potential waveform of cultured $P D Y N^{\mathrm{R} 212 \mathrm{~W}}$ cerebellar neurons affecting neuronal excitability.

\section{Discussion}

In this study, we generated the first mouse model for SCA23 and shown that mice expressing PDYN-R212W recapitulate many characteristics of the human phenotype of SCA23 (Verbeek et al., 2004). PDYN ${ }^{\mathrm{R} 212 \mathrm{~W}}$ mice develop mild, slowly progressing ataxia, with subtle gait abnormalities detected at 3 months of age, and an overall decline in motor performance at 12 months of age, related to synaptic alterations in Purkinje cells (early) and Purkinje cell loss (later), coinciding with elevated mutant dynorphin A peptide levels. The loss of climbing fibre-Purkinje cell synapses most likely contributes to the early motor deficits in $P D Y N^{\mathrm{R} 212 \mathrm{~W}}$ mice, by causing Purkinje cell malfunctioning and eventually cell death. The observation that the climbing fibre retraction is progressive, suggests that loss of climbing fibre-Purkinje cell synapses is caused by active elimination, rather than by a developmental issue (Ebner et al., 2013). Additionally, loss of climbing fibre-Purkinje cell synapses seems to be common in SCA pathology including SCA1, SCA7 and SCA14 (Duvick et al., 2010; Shuvaev et al., 2011; Furrer et al., 2013). However, the relative mild pathology of the PDYN ${ }^{\mathrm{R} 212 \mathrm{~W}}$ mice correlates more with the conventional (non-polyglutamine) SCA5 mouse model, which displayed Purkinje cell loss from 6 months of age (Perkins et al., 2010). The region most affected by neurodegeneration was the anterior vermis, a region known to be involved in motor coordination and balance (Manni and Petrosini, 2004; Stoodley and Schmahmann, 2010), again mimicking the human disease (Verbeek et al., 2004). The question remains why $P D Y N^{\mathrm{R} 212 \mathrm{~W}}$ mice show relatively restricted cerebellar pathology. We hypothesize that mutant dynorphin A is mimicking the actions of glutamate, and selectively targets NMDA receptors comprised of NR2A and NR2B subunits instead of its native opioid receptors. These NMDA receptors mainly mediate

\section{Figure 5 Continued}

PDYN $^{\mathrm{WT}}$ mice and littermate controls. PDYN ${ }^{\mathrm{R} 212 \mathrm{~W}}$ mice at 12 months of age stayed on average $38.99 \pm 2.67 \mathrm{~s}$ on the accelerating rod compared to PDYN ${ }^{\mathrm{WT}}$ mice and littermate controls, which stayed on the rod for $61.32 \pm 4.56$ and $81.34 \pm 5.40 \mathrm{~s}$, respectively. One-way ANOVA, $* P<0.05$. 
A
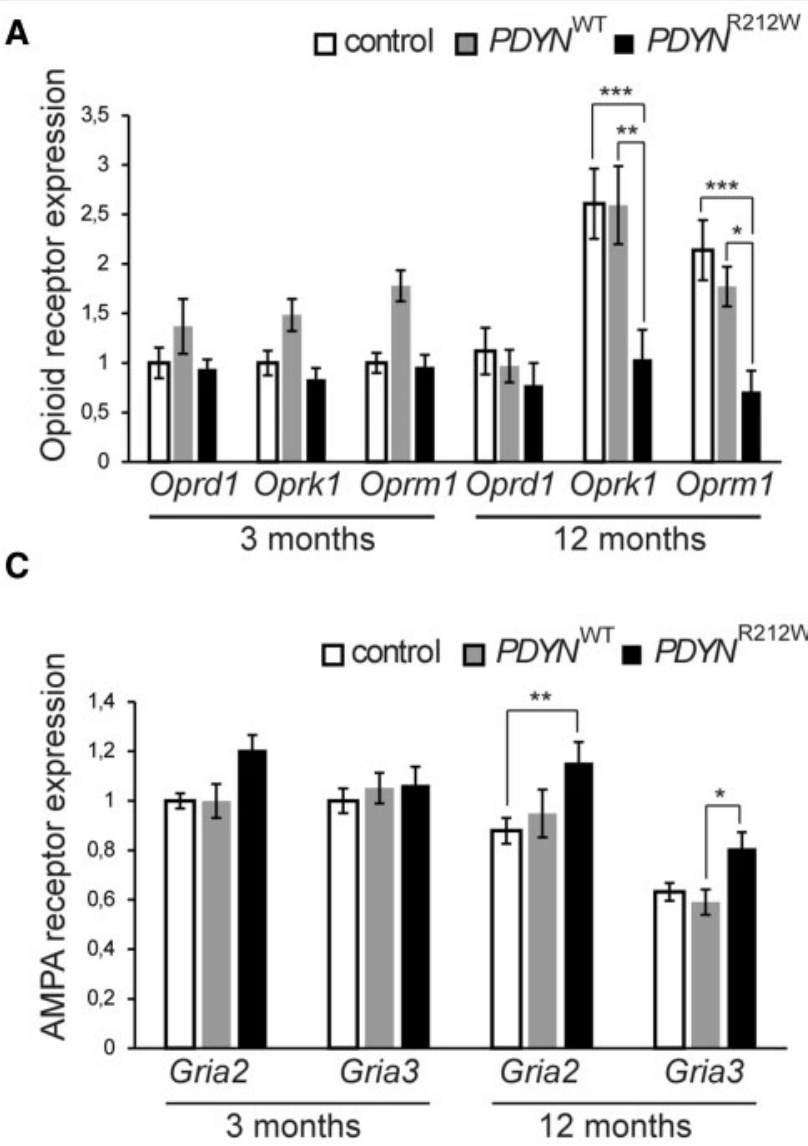
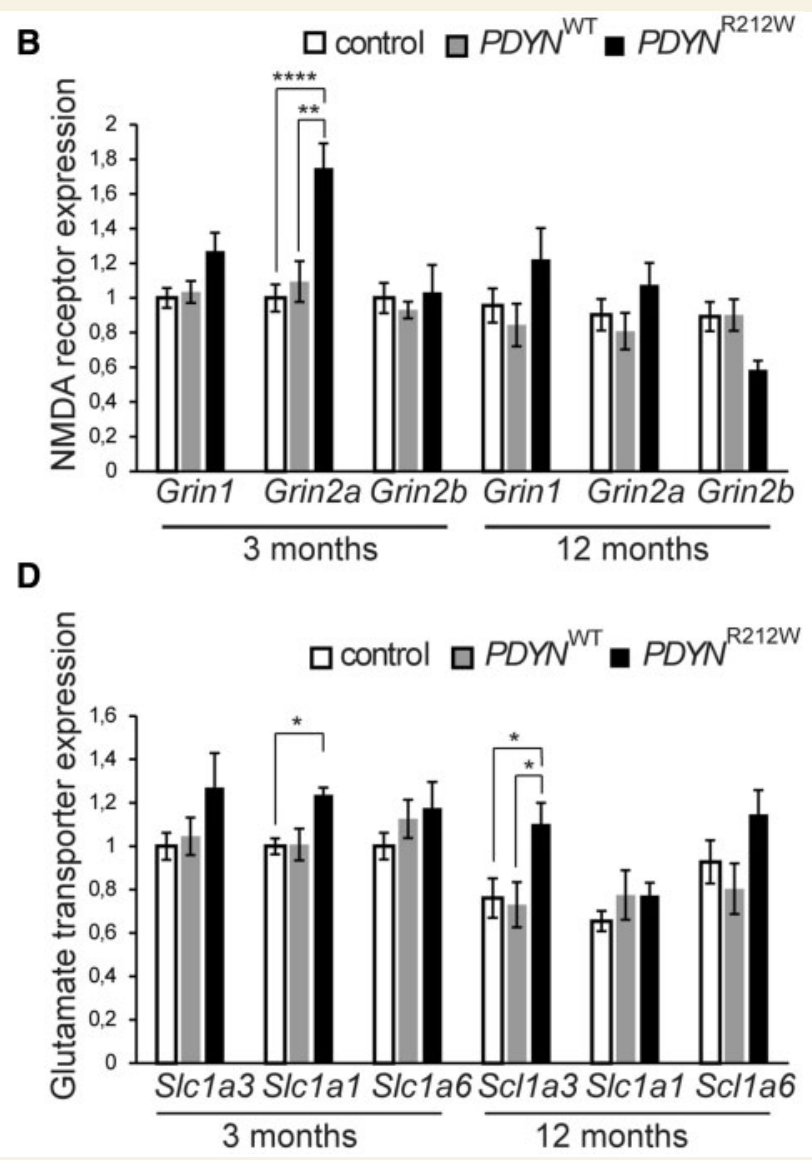

Figure 6 Altered expression of opioid receptors and glutamatergic signalling components in cerebella of PDYN ${ }^{\mathrm{R} 2 I 2 \mathrm{~W}}$ mice. Quantification of RT-PCR data of 3- and I2-month old cerebella of control, PDYN ${ }^{W T}$ and PDYN ${ }^{R 2 I 2 W}$ mice $(n=6$, per genotype). All data were normalized to 3-month-old controls. (A) At 3 months of age, no significant difference was observed between the expression of the opioid receptors between the three genotypes. At 12 months of age, both PDYN ${ }^{W T}$ and control mice showed significantly increased ( 2.5-fold each) OprkI and Oprm I mRNA expression compared to PDYN ${ }^{R 212 \mathrm{~W}}$ mice. This increase in receptor mRNA expression over time was only significant (OprkI, $P<0.0001$ and Oprm I, $P<0.0002$ ) for control mice and not for PDYN ${ }^{W T}$ mice. $* P<0.05$, $* * P<0.01$ and $* * * P<0.00 I$. (B) Grin2a mRNA expression was only significantly increased by $\sim 1.7$ - and $\sim 1.6$-fold in 3-month-old PDYN ${ }^{R 212 W}$ mice compared to PDYN ${ }^{W T}$ and control mice, respectively. This was effect was no longer observed at 12 months of age. No significantly differences were detected in the mRNA expression of Grin I and Grin $2 b$ between the genotypes or over time. $* * P<0.01$ and $* * * * P<0.000$ I. (C) No significant changes in Gria2 and Gria3 mRNA expression were detected between the various genotypes at 3 months of age. At 12 months, both Gria2 and Gria3 mRNA expression was significantly increased (Gria2, I.3-fold and Gria3, I.4-fold) in PDYN ${ }^{\mathrm{R} 212 \mathrm{~W}}$ mice compared to PDYN ${ }^{\mathrm{WT}}$ and control mice, respectively. However, this difference in mRNA expression levels was due to a decline in Gria2 and Gria3 mRNA expression in PDYN ${ }^{W T}$ and control mice. *P $<0.05$ and **P $<0.01$. (D) Slclal mRNA expression was $\sim 1.2$-fold increased in 3-month-old PDYN ${ }^{R 212 W}$ mice, compared to control mice, that was no longer observed at 12 months of age. However, SIcla 3 mRNA expression was $\sim 1.5$-fold increased in PDYN ${ }^{R 212 W}$ mice compared to both PDYN ${ }^{W T}$ and control mice at 12 months of age. The Slcla6 mRNA expression levels did not differ between the genotypes, or over time. $* P<0.05$.

excitatory post synaptic potentials on Purkinje cells at Purkinje cell-climbing fibre synapses (Renzi et al., 2007), and overactivation may contribute to retraction of climbing fibres, affecting intracellular calcium concentrations and induction of cerebellar plasticity which plays an important role in preserving motor performance (Hansel et al., 2001; Cerminara and Rawson, 2004; Hirano, 2013).

This work confirms our previous genetic and cellular findings (Bakalkin et al., 2010), and shows that the $\mathrm{R} 212 \mathrm{~W}$ mutation in PDYN results in elevated dynorphin A levels in vivo and causes cerebellar ataxia. The elevated dynorphin A peptide levels are probably the result of enhanced PDYN-R212W processing, as low precursor protein levels were detected in $P D Y N^{\mathrm{R} 212 \mathrm{~W}}$ mice. Additionally, the $\mathrm{R} 212 \mathrm{~W}$ mutation may stabilize the mutant peptide, as unchanged levels of the peptide cleavage product, Leu-ENK-Arg ${ }^{6}$, were observed. This suggests that mutant dynorphin A is degraded less efficiently, leading to accumulation of mutant dynorphin A, but not dynorphin $\mathrm{B}$, in the tissue. Additionally, the elevated levels of mutant dynorphin A are very likely the cause of Purkinje cell death and cerebellar ataxia.

Previous studies have already shown that dynorphin A can cause cytotoxicity through various non-opioid mechanisms (Hauser et al., 1999; Tan-No et al., 2001; Singh et al., 2002, 2003; Sherwood and Askwith, 2009). Here, the 
A

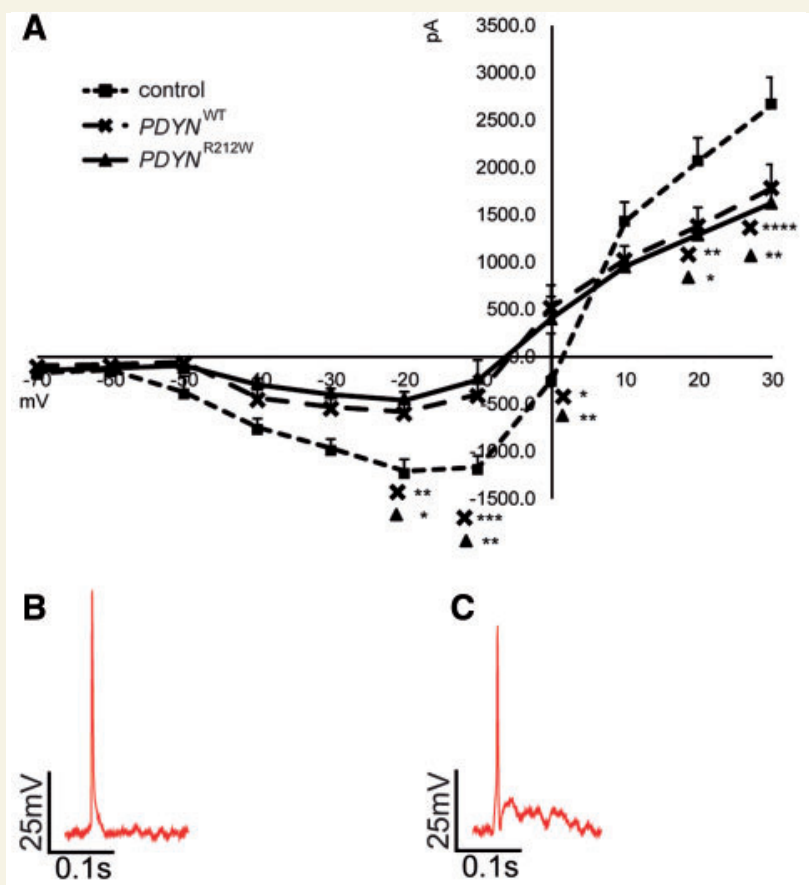

Avg voltage $61.8 \pm 3.1 \mathrm{mV}$ Avg half-width $2.6 \pm 0.3 \mathrm{~ms}$

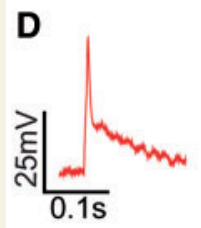

Avg voltage $37 \pm 2.4 \mathrm{mV}$ Avg half-width $9.7 \pm 1.1 \mathrm{~ms}$ Avg half-width $2 \pm 0.1 \mathrm{~ms}$

\section{E}

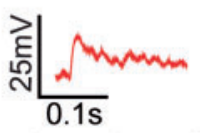

Avg voltage $6.2 \pm 0.4 \mathrm{mV}$ Avg half-width $35.4 \pm 4.4 \mathrm{~ms}$
Avg voltage $66.9 \pm 3.1 \mathrm{mV}$

Figure 7 Voltage clamp recordings show loss of action potential peak in PDYN ${ }^{\mathrm{R} 2 \mathrm{I} 2 \mathrm{~W}}$ cultured cerebellar neurons. (A) Combined $\mathrm{Na}^{+}$and $\mathrm{K}^{+}$IV curves for control, PDYN ${ }^{\mathrm{WT}}$, and $P D Y N^{R 212 W}$ cultured neurons show significantly less electrical charge of the membrane of PDYN ${ }^{\mathrm{WT}}$ and PDYN ${ }^{\mathrm{R} 212 \mathrm{~W}}$ neurons than of control neurons. $* P<0.05$, **P $<0.01$, ***P $<0.001$, and $* * * * P<0.0001$, cross for PDYN ${ }^{W T}$ versus control, triangle for $P D Y N^{R 212 W}$ versus control. (B-E) Representative action potential waveforms. Control neuron action potentials consisted of $61.8 \pm 3.1 \mathrm{mV}$ and had a half-width of $2.6 \pm 0.3 \mathrm{~ms}(\mathrm{~B})$, PDYN WT action potentials had a first peak of $66.9 \pm 3.1 \mathrm{mV}$ and a half-width of $2.0 \pm 0.1 \mathrm{~ms}(\mathbf{C})$, and PDYN ${ }^{R 212 \mathrm{~W}}$ neurons showed action potentials consisting of $37.0 \pm 2.4 \mathrm{mV}$ and had a half-width of $9.7 \pm 1.1 \mathrm{~ms}(\mathbf{D})$ and excitatory post synaptic potentials of $6.2 \pm 0.4 \mathrm{mV}$ and a half-width of $35.4 \pm 4.4 \mathrm{~ms}(\mathrm{E})$. Expression of PDYN-R2 I $2 \mathrm{~W}$ caused changes in the action potential waveform of cultured $P D Y N^{R 212 W}$ cerebellar neurons, impairing neuronal activity.

increased mRNA levels of the NMDA-R subunit Grin2a, which is the major contributor of NMDA-R-mediated excitotoxicity (Engelhardt et al., 2006), in $P D Y N^{\mathrm{R} 212 \mathrm{~W}}$ mice at 3 months of age make it tantalizing to speculate that mutant dynorphin A is (over)stimulating NMDA-Rs containing this subunit. Notably, dynorphin A was previously

shown to directly interact with the NMDA-R and potentiates its glutamate currents (Woods et al., 2006). The temporal decrease in mRNA expression of the Grin2a subunit may be a compensatory mechanism of the cells trying to decrease the NMDA-R-induced excitatory post synaptic potentials that may be caused by the elevated Grin $2 a$ mRNA levels (Renzi et al., 2007). Additionally, PDYN ${ }^{\mathrm{R} 212 \mathrm{~W}}$ mice highly express glutamate transporters and AMPA-R subunits at 12 months of age. Increases in glutamate transporters may suggest that Purkinje cells and Bergmann glia perceive a high concentration of extracellular glutamate and attempt to clear this from the synaptic cleft. The changes in the mRNA expression of AMPA-R subunits may disturb the induction of cerebellar plasticity (Miyazaki et al., 2010). Additionally, AMPA-R-mediated excitotoxicity was proposed as the underlying mechanism of Purkinje cell loss in SCA5 (Perkins et al., 2010).

Another possible mechanism may be increased opioidmediated glutamate release, where mutant dynorphin A interacts with presynaptically located kappa-opioid receptor to induce release of glutamate, thereby indirectly activating NMDA-Rs (Kuzmin et al., 2013). However, given the reduced mRNA expression of Oprk1 in PDYN ${ }^{\mathrm{R} 212 \mathrm{~W}}$ mice at 12 months of age, and the reduced affinity of mutant dynorphin A to bind to kappa-opioid receptor (unpublished data), this mechanism seems unlikely.

In addition, evidence is accumulating that dynorphin Amediated neurotoxicity may be non-receptor-mediated, as dynorphin A peptides were shown to interact with membranes, induce membrane leakage, and translocate across the plasma membrane, which could underlie neuronal cell death (Marinova et al., 2005; Madani et al., 2011; Björnerås et al., 2013). Interestingly, similar mechanisms have been reported for the cytotoxicity of amyloid- $\beta$ in Alzheimer's disease, where amyloid- $\beta$ peptides were shown to activate extrasynaptic NMDA-Rs indirectly, leading to synaptic loss and/or changes in the permeability of membranes after inducing pore formations leading to increased amyloid formation and toxicity in vivo (Lashuel et al., 2003; Sepulveda et al., 2010; Nagarathinam et al., 2013; Talantova et al., 2013).

The altered neuronal excitability as indicated by the distinct change in the amplitude and action potential waveform in cultured cerebellar neurons of $P D Y N^{\mathrm{R} 212 \mathrm{~W}}$ mice compared to $P D Y N^{\mathrm{WT}}$ and control cerebellar neurons likely indicate that expression of PDYN-R212W affects synaptic transmission. The spikelets cause little depolarization of the membrane, exhibit slow extinction affecting repolarization, and do not show overshoot fast spikes like PDYN ${ }^{\mathrm{WT}}$ and control neurons, showing resemblance to an immature phenotype of granule cells (Prestori et al., 2008). As the cerebellar neurons examined here demonstrated action potential waveforms attributed to different cell populations including granule cells (Huang et al., 1993), the relevance of these results with regard to Purkinje cell functioning need to be further investigated. This data complements our hypothesis of that expression 


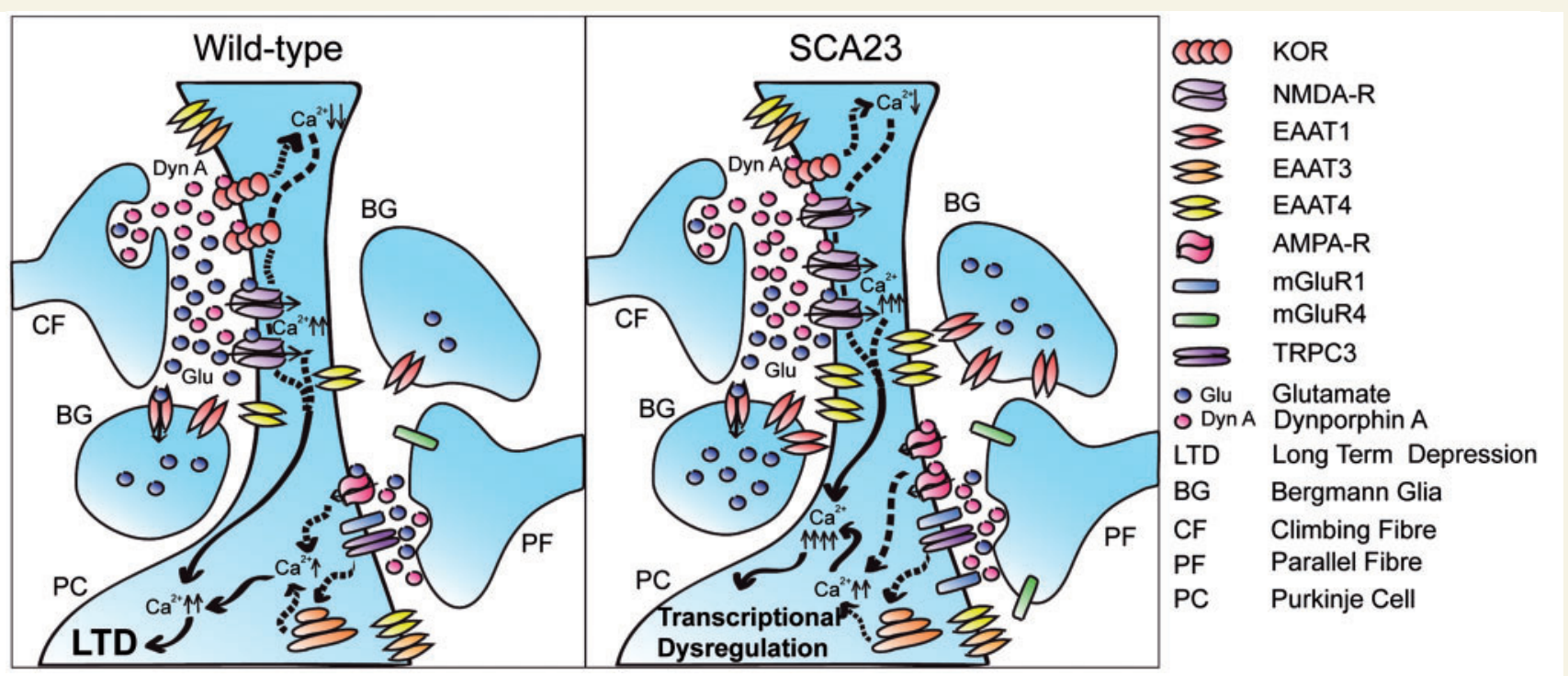

Figure 8 Potential disease mechanism of SCA23. Under normal conditions (left), climbing fibre action potentials lead to secretion of glutamate into the synaptic cleft, which binds and activates the NMDA receptor leading to a rise in the intracellular calcium concentration. During paired climbing fibre-parallel fibre action potentials, the intracellular calcium level can rise high enough to induce long term depression via the internalization of AMPA-Rs at the parallel fibre-Purkinje cell synapse. Wild-type dynorphin A is also secreted into the synapse and preferentially binds the kappa-opioid receptor, leading to a reduction of intracellular calcium levels and thereby regulating calcium homeostasis. In SCA23 (right), dynorphin $A$ is mutated and present in much higher levels than in wild type cerebellum, and may activate the NMDA-R, very likely mimicking the actions of glutamate. We hypothesize that the mutant dynorphin A presumably does not get cleared by glutamate transporters like the excitatory amino acid transporters and lingers in the synaptic cleft and its surroundings, activating available receptors. Alternatively, mutant dynorphin A releases synaptic glutamate, via yet unknown mechanisms leading to increased expression of glutamate receptors and transporters. Nevertheless, due to either excess mutant dynorphin A and/or excess glutamate, NMDA receptors get overstimulated, and intracellular calcium levels are not controlled properly due to reduced levels of kappa-opioid receptor in SCA23 cerebellum. We therefore hypothesize that the Purkinje cells in SCA23 cerebellum suffer from pathologically uncontrolled intracellular calcium levels, which may lead to transcriptional dysregulation, and eventually neuronal cell death.

of PDYN-R212W may cause altered synaptic efficiency, as information transfer at synapses is based upon changes in membrane polarization. Additionally, this finding could support the idea that mutant dynorphin A induces membrane leakage by interacting with the membrane and induces pores in the membrane (Marinova et al., 2005; Madani et al., 2011; Björnerås et al., 2013), thereby changing the membrane potential and impeding expression of action potentials.

In conclusion, the PDYN ${ }^{\mathrm{R} 212 \mathrm{~W}}$ mouse is the first mouse model for SCA23, and it recapitulates the symptoms and cerebellar pathology of patients with SCA23. We show that the elevated mutant dynorphin A peptide levels are very likely responsible for the initiation and progression of SCA23 disease, and cause alterations in climbing fibrePurkinje cell synapse function and motor performance. Although the mechanism by which mutant dynorphin A causes neurotoxicity is not completely revealed, our results show that high levels of mutant dynorphin A correlate with increased expression of glutamate receptors, including NMDA-R and AMPA-R subunits that may cause intracellular calcium levels to increase, leading to transcriptional dysregulation and conceivably neurotoxicity (Fig. 8). However, given the electrophysiological data, non-receptor mediated neurotoxicity could also underlie the pathology of SCA23.

Nevertheless, our mouse model provides unique opportunities to study the disease progression of a pure, isolated spinocerebellar ataxia during chronological ageing in more detail, because mutant mice develop their symptoms slowly. Moreover, our model may be of value beyond understanding SCA23 only, as elevated dynorphin A levels have also been linked to the pathology of Alzheimer's disease (Yakovleva et al., 2007), supporting a more general implication of elevated opioid neuropeptides levels in the aetiology of neurodegenerative disorders.

\section{Acknowledgement}

We would like to thank Jackie Senior for editing this manuscript.

\section{Funding}

This work was funded by a Rosalind Franklin Fellowship from the University of Groningen, and the $\mathrm{U} 4 \mathrm{PhD}$ program of the Behavioral and Cognitive Neuroscience 
graduate school of the University of Groningen (to DSV), and by Swedish research councils Vetenskapsrådet, FAS and FORMAS (to G.B.). Part of this work was performed at the University Medical Centre Groningen Microscopy and Imaging Centre, which is sponsored by the Netherlands Organization for Scientific Research (NWO grants 40-00506-98-9021 and 175-010-2009-023).

\section{Supplementary material}

Supplementary material is available at Brain online.

\section{References}

Akil H, Watson SJ, Young E, Lewis ME, Khachaturian H, Walker JM. Endogenous opioids: biology and function. Annu Rev Neurosci 1984; 7: 223-55.

Bakalkin G, Watanabe H, Jezierska J, Depoorter C, VerschuurenBemelmans C, Bazov I, et al. Prodynorphin mutations cause the neurodegenerative disorder spinocerebellar ataxia type 23. Am J Hum Genet 2010; 87: 593-603.

Baker DJ, Dawlaty MM, Wijshake T, Jeganathan KB, Malureanu L, van Ree JH, et al. Increased expression of BubR1 protects against aneuploidy and cancer and extends healthy lifespan. Nat Cell Biol 2013; 15: 96-102.

Björnerås J, Gräslund A, Mäler L. Membrane interaction of diseaserelated dynorphin a variants. Biochemistry 2013; 52: 4157-67.

Brooks SP, Dunnett SB. Tests to assess motor phenotype in mice: a user's guide. Nat Rev Neurosci 2009; 10: 519-29.

Cerminara NL, Rawson JA. Evidence that climbing fibers control an intrinsic spike generator in cerebellar Purkinje cells. J Neurosci 2004; 24: 4510-17.

Chavkin C. Dynorphin-still an extraordinarily potent opioid peptide. Mol Pharmacol 2013; 83: 729-36.

Christensson-Nylander I, Nyberg F, Ragnarsson U, Terenius L. A general procedure for analysis of proenkephalin $\mathrm{B}$ derived opioid peptides. Regul Pept 1985; 11: 65-76.

Duvick L, Barnes J, Ebner B, Agrawal S, Andresen M, Lim J, et al. SCA1-like disease in mice expressing wild-type ataxin-1 with a serine to aspartic acid replacement at residue 776. Neuron 2010; 67: 929-35.

Ebner BA, Ingram MA, Barnes JA, Duvick LA, Frisch JL, Clark HB, et al. Purkinje cell ataxin-1 modulates climbing fiber synaptic input in developing and adult mouse cerebellum. J Neurosci 2013; 33: 5806-20.

Engelhardt von J, Coserea I, Pawlak V, Fuchs EC, Köhr G, Seeburg $\mathrm{PH}$, et al. Excitotoxicity in vitro by NR2A- and NR2B-containing NMDA receptors. Neuropharmacology 2006; 53: 10-17.

Fremeau RT, Troyer MD, Pahner I, Nygaard GO, Tran CH, Reimer $\mathrm{RJ}$, et al. The expression of vesicular glutamate transporters defines two classes of excitatory synapse. Neuron 2001; 31: 247-60.

Furrer SA, Waldherr SM, Mohanachandran MS, Baughn TD, Nguyen $\mathrm{K}-\mathrm{T}$, Sopher BL, et al. Reduction of mutant ataxin-7 expression restores motor function and prevents cerebellar synaptic reorganization in a conditional mouse model of SCA7. Hum Mol Genet 2013; 22: 890-903.

Hansel C, Linden DJ, D'Angelo E. Beyond parallel fiber LTD: the diversity of synaptic and non-synaptic plasticity in the cerebellum. Nat Neurosci 2001; 4: 467-475.

Hauser KF, Aldrich JV, Anderson KJ, Bakalkin G, Christie MJ, Hall $\mathrm{ED}$, et al. Pathobiology of dynorphins in trauma and disease. Front Biosci 2005; 10: 216-35.
Hauser KF, Foldes JK, Turbek CS. Dynorphin A (1-13) neurotoxicity in vitro: opioid and non-opioid mechanisms in mouse spinal cord neurons. Exp Neurol 1999; 160: 361-75.

Herman BH, Leslie F, Goldstein A. Behavioral effects and in vivo degradation of intraventricularly administered dynorphin-(1-13) and D-Ala2-dynorphin-(1-11) in rats. Life Sci 1980; 27: 883-92.

Hirano T. Long-term depression and other synaptic plasticity in the cerebellum. Proc Jpn Acad Ser B Phys Biol Sci 2013; 89: 183-95.

Huang $\mathrm{CM}, \mathrm{Mu} \mathrm{H}$, Hsiao CF. Identification of cell types from action potential waveforms: cerebellar granule cells. Brain Res 1993; 619: 313-18.

Kotz CM, Weldon D, Billington CJ, Levine AS. Age-related changes in brain proDynorphin gene expression in the rat. Neurobiol Aging 2004; 25: 1343-7.

Kuzmin A, Chefer V, Bazov I, Meis J, Ögren SO, Shippenberg T, et al. Upregulated dynorphin opioid peptides mediate alcohol-induced learning and memory impairment. Transl Psychiatry 2013; 3: e310.

Lai J, Luo M-C, Chen Q, Ma S, Gardell LR, Ossipov MH, et al. Dynorphin A activates bradykinin receptors to maintain neuropathic pain. Nat Neurosci 2006; 9: 1534-40.

Lashuel HA, Hartley DM, Petre BM, Wall JS, Simon MN, Walz T, et al. Mixtures of wild-type and a pathogenic (E22G) form of Abeta40 in vitro accumulate protofibrils, including amyloid pores. J Mol Biol 2003; 332: 795-808.

Madani F, Taqi MM, Wärmländer SKTS, Verbeek DS, Bakalkin G, Gräslund A. Perturbations of model membranes induced by pathogenic dynorphin A mutants causing neurodegeneration in human brain. Biochem Biophys Res Commun 2011; 411: 111-14.

Manni E, Petrosini L. A century of cerebellar somatotopy: a debated representation. Nat Rev. Neurosci 2004; 5: 241-9.

Manto M, Marmolino D. Cerebellar ataxias. Curr Opin Neurol 2009; 22: 419-29.

Marinova Z, Vukojevic V, Surcheva S, Yakovleva T, Cebers G, Pasikova N, et al. Translocation of dynorphin neuropeptides across the plasma membrane. A putative mechanism of signal transmission. J Biol Chem 2005; 280: 26360-70.

Merg F, Filliol D, Usynin I, Bazov I, Bark N, Hurd YL, et al. Big dynorphin as a putative endogenous ligand for the kappa-opioid receptor. J Neurochem 2006; 97: 292-301.

Ménard C, Tse YC, Cavanagh C, Chabot J-G, Herzog H, Schwarzer $\mathrm{C}$, et al. Knockdown of prodynorphin gene prevents cognitive decline, reduces anxiety, and rescues loss of group 1 metabotropic glutamate receptor function in aging. J Neurosci 2013; 33: 12792804.

Miyazaki T, Yamasaki M, Takeuchi T, Sakimura K, Mishina M, Watanabe M. Ablation of glutamate receptor GluR $\delta 2$ in adult Purkinje cells causes multiple innervation of climbing fibers by inducing aberrant invasion to parallel fiber innervation territory. J Neurosci 2010; 30: 15196-209.

Nagarathinam A, Höflinger P, Bühler A, Schäfer C, McGovern G, Jeffrey $M$, et al. Membrane-anchored $A \beta$ accelerates amyloid formation and exacerbates amyloid-associated toxicity in mice. J Neurosci 2013; 33: 19284-94.

Nichol PF, Botham R, Saijoh Y, Reeder AL, Zaremba KM. A more efficient method to generate null mutants using Hprt-Cre with floxed alleles. J Pediatr Surg 2011; 46: 1711-19.

Perkins EM, Clarkson YL, Sabatier N, Longhurst DM, Millward CP, Jack J, et al. Loss of beta-III spectrin leads to Purkinje cell dysfunction recapitulating the behavior and neuropathology of spinocerebellar ataxia type 5 in humans. J Neurosci 2010; 30: 4857-67.

Prestori F, Rossi P, Bearzatto B, Lainé J, Necchi D, Diwakar S, et al. Altered neuron excitability and synaptic plasticity in the cerebellar granular layer of juvenile prion protein knock-out mice with impaired motor control. J Neurosci 2008; 28: 7091-103.

Renzi M, Farrant M, Cull-Candy SG. Climbing-fibre activation of NMDA receptors in Purkinje cells of adult mice. J Physiol (Lond) 2007; 585: 91-101. 
Sepulveda FJ, Parodi J, Peoples RW, Opazo C, Aguayo LG. Synaptotoxicity of Alzheimer beta amyloid can be explained by its membrane perforating property. PLoS One 2010; 5: e11820.

Sherwood TW, Askwith CC. Dynorphin opioid peptides enhance acidsensing ion channel 1a activity and acidosis-induced neuronal death. J Neurosci 2009; 29: 14371-80.

Shuvaev AN, Horiuchi H, Seki T, Goenawan H, Irie T, Iizuka A, et al. Mutant $\mathrm{PKC} \gamma$ in spinocerebellar ataxia type 14 disrupts synapse elimination and long-term depression in Purkinje cells in vivo. J Neurosci 2011; 31: 14324-34.

Singh IN, Goody RJ, Goebel SM, Martin KM, Knapp PE, Marinova $\mathrm{Z}$, et al. Dynorphin A (1-17) induces apoptosis in striatal neurons in vitro through @a-amino-3-hydroxy-5-methylisoxazole-4-propionate/kainate receptor-mediated cytochrome $\mathrm{C}$ release and caspase-3 activation. Neuroscience 2002; 122: 11.

Singh IN, Goody RJ, Goebel SM, Martin KM, Knapp PE, Marinova $Z$, et al. Dynorphin A (1-17) induces apoptosis in striatal neurons in vitro through alpha-amino-3-hydroxy-5-methylisoxazole-4-propionate/kainate receptor-mediated cytochrome $\mathrm{c}$ release and caspase- 3 activation. Neuroscience 2003; 122: 1013-23.

Stoodley CJ, Schmahmann JD. Evidence for topographic organization in the cerebellum of motor control versus cognitive and affective processing. Cortex 2010; 46: 831-44.

Talantova M, Sanz-Blasco S, Zhang X, Xia P, Akhtar MW, Okamoto SI, et al. A $\beta$ induces astrocytic glutamate release, extrasynaptic NMDA receptor activation, and synaptic loss. Proc Natl Acad Sci USA 2013; 110: E2518-27.
Tan-No K, Cebers G, Yakovleva T, Hoon Goh B, Gileva I, Reznikov $\mathrm{K}$, et al. Cytotoxic effects of dynorphins through nonopioid intracellular mechanisms. Exp Cell Res 2001; 269: 54-63.

van Ree JH, Jeganathan KB, Malureanu L, van Deursen JM. Overexpression of the E2 ubiquitin-conjugating enzyme UbcH10 causes chromosome missegregation and tumor formation. J Cell Biol 2010; 188: 83-100.

Verbeek DS, Van De Warrenburg BP, Wesseling P, Pearson PL, Kremer HP, Sinke RJ. Mapping of the SCA23 locus involved in autosomal dominant cerebellar ataxia to chromosome region 20p13-12.3. Brain 2004; 127: 2551-7.

Walker JM, Moises HC, Coy DH, Baldrighi G, Akil H. Nonopiate effects of dynorphin and des-Tyr-dynorphin. Science 1982; 218: 1136-8.

Watanabe HH, Mizoguchi HH, Verbeek DSD, Kuzmin AA, Nyberg FF, Krishtal OO, et al. Non-opioid nociceptive activity of human dynorphin mutants that cause neurodegenerative disorder spinocerebellar ataxia type 23. Peptides 2012; 35: 306-10.

Woods AS, Kaminski R, Oz M, Wang Y, Hauser K, Goody R, et al. Decoy peptides that bind dynorphin noncovalently prevent NMDA receptor-mediated neurotoxicity. J Proteome Res 2006; 5: 1017-23. Yakovleva T, Bazov I, Cebers G, Marinova Z, Hara Y, Ahmed A, et al. Prodynorphin storage and processing in axon terminals and dendrites. FASEB J 2006; 20: 2124-6.

Yakovleva T, Marinova Z, Kuzmin A, Seidah NG, Haroutunian V, Terenius L, et al. Dysregulation of dynorphins in Alzheimer disease. Neurobiol Aging 2007; 28: 1700-8. 